\title{
FLOW ANALYSIS OF LAMBDA EXPRESSIONS
}

by

Neil D. Jones

DAIMI PB- 128

January 1981

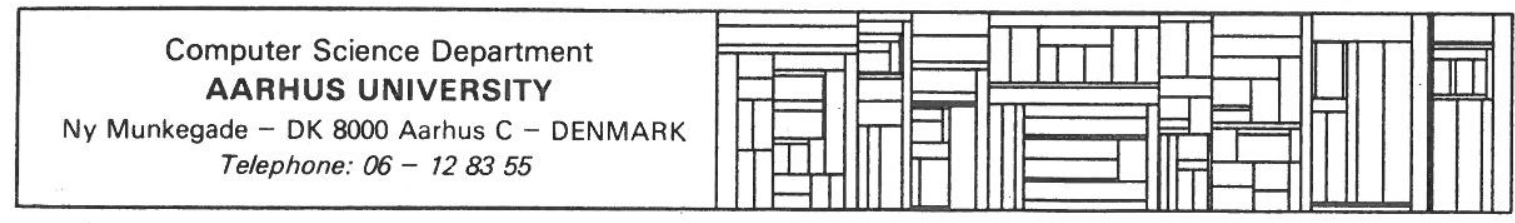


FLOW ANALYSIS OF LAMBDA EXPRESSIONS

Neil D. Jones

Aarhus University, Denmark

\section{INTRODUCTION}

\section{Overview}

Program flow analysis determines properties of the computation(s) induced by a program without actually running it. The purpose is usually to extract information which may be used to optimize the program, compile code, certify the absence of certain runtime errors, etc. Excellent introductions to flow analysis may be found in [Hec77] and [Aho77].

We describe a method to analyze the data and control flow during mechanical evaluation of lambda expressions. The method produces a finite approximate description of the set of all states entered by a call-by-value $\lambda$-calculus interpreter; a similar approach can easily be seen to work for call-by-name. A proof is given that the approximation is "safe", i.e. that it includes descriptions of every intermediate $\lambda$-expression which occurs in the evaluation.

From a programming languages point of view the method extends previously developed interprocedural analysis methods to include both local and global variables, call-by-name or call-by-value parameter transmission and the use of procedures both as arguments to other procedures and as the results returned by them.

The main emphasis is on development of the flow analysis framework rather than on applications, although a few are given (termination, finiteness, dependence, constant propagation). Other familiar analyses easily fit into the same framework, e.g. available expressions and deciding whether a base function's arguments always have the right type.

The information gathered could be used to compile unusually efficient code for programming languages based on the $\lambda$-calculus such as LISP and SCHEME [Ste76]. Hopefully it will be possible to extend these methods to the flow analysis of denotational definitions. The use of such analyses in compiler generation was described in [JoS80] and provided the initial motivation for this study.

The methods developed here are not limited to the $\lambda$-calculus, but may be applied to any programming language whose semantics are specified by (or specifiable) by a definitional interpreter using recursively defined data structures. The $\lambda$-calculus was chosen because of the challenge of tracing control and data flow in 
a computation; it provides a "worst-case" example of many problems encountered in interprocedural analysis.

\section{Related Work}

Lambda calculus machines include the SECD and CUCH machines of Landin and Böhm ([Lan64], [Böh72]) and those due to Reynolds, Wegner and McGowan ([Rey72], [Weg68], [McG70]). McGowan and Plotkin ([McG70], [Plo75]) have proved correctness of their machines, and Plotkin further investigates a number of questions concerning call-by-name and call-by-value.

Interprocedural flow analysis has been investigated by (among others) Rosen, Cousot and Cousot, and Sharir and Pnueli ([Ros79], [Cou77], [Sha80]). Levy has developed sufficient conditions for termination of $\beta$-reduction sequences in [Lev75], and Mycroft ( $[\mathrm{Myc} 80])$ developed sufficient conditions for the replacement of callby-need by call-by-value in schemes of recursion equations using the flow analytic idea of "abstract interpretation". Pleban is currently doing a flow analysis of the SCHEME language, expressed using denotational semantics [Ple80].

\section{Outline of the Paper}

In the first section we introduce the OI interpreter, a nondeterministic machine which can perform an arbitrary sequence of outside-in $\beta$ - and $\delta$-reductions on a closed lambda expression. The initial state of the Ol interpreter for input $M_{0}$ will be Load $\left(M_{0}\right)$, and every $O I$ state $\sigma$ will represent a $\lambda$-expression Unload $(\sigma)$. A computation Load $\left(M_{0}\right)=\sigma_{0} \Rightarrow \sigma_{1} \Rightarrow \sigma_{2} \Rightarrow \ldots$ will correspond to a series of $\beta$-reductions, $\delta$-reductions or identity transformations.

There are two reasons for introducing yet another $\lambda$-calculus interpreter. First, the Ol machine can naturally be restricted to yield deterministic call-byname and call-by-value submachines CBN and CBV. While we analyze only CBV (because of its similarity with existing programming languages) it will be apparent that CBN can be analyzed by the same methods. Second, both CBV and CBN seem to be significantly simpler than other $\lambda$-calculus interpreters, which in turn simplifies our model-building process. The appendix ${ }^{*}$ contains correctness proofs for these machines.

Section 2 develops analysis methods for a closed $\lambda$-expression $M_{0}$ without constants; this we call the control flow analysis of the call-by-value computation. The result of this is a safe description of

States $\left(M_{0}\right)=\left\{\sigma \mid C B V\right.$ enters state $\sigma$ during its computation on $\left.M_{0}\right\}$

* Appendix omitted in this preliminary version. 
A lattice $D$ will be defined whose elements $\delta$ will each describe a set of states. An effectively computable method will be described to obtain from $M_{0}$ a description $\delta\left(M_{0}\right) \in D$. It will be proven that this description is "safe" in the sense that every state $\sigma \in$ States $\left(M_{0}\right)$ is represented in $\delta\left(M_{0}\right)$. Safeness implies that answers to questions about the computation which can be answered by examination of $\delta\left(M_{0}\right)$ can at worst err "on the safe side", since every state in States $\left(M_{0}\right)$ is accounted for. However precise answers cannot be given to all such questions since some (such as the halting problem) are undecidable. Technically this occurs since $D$ is finite, with size recursively bounded in the size of $M_{0}$, so some information must be lost.

Section 2 concludes by constructing a context-free grammar $G\left(M_{0}\right)$ which generates linear representations of all $\sigma$ in States $\left(M_{0}\right)$, followed by a proof that safe answers may be computably obtained to several questions about the computation.

Section 3 extends the method to handle $\lambda$-expressions with constants and $\delta-$ reduction, using an approximation lattice to describe effectively sets of constant values. An example is given which is suitable for constant propagation, i. e. to find out which variables only receive constant values, and what those values are. Applications to error-checking and type-correctness of base functions are considered.

Section 4 ends with conclusions, future directions and acknowledgments.

\section{Notational Conventions}

The power set of $X$, written $P(X)$ is the set of all subsets of $X$.

Given sets $X$ and $Y, X \stackrel{P}{\Rightarrow} Y$ is the set of partial functions from $X$ to $Y$. Given $f \in(X \stackrel{P}{\Rightarrow} Y)$, Domain( $f)$ is its domain. Two functions in $X \stackrel{P}{\Rightarrow} Y$ are equal iff their domains are equal and they have the same values on arguments for which they are defined. If $x \in X, y \in Y$ and $f \in X \stackrel{P}{\Rightarrow} Y$ then $f\{y / x\}$ denotes the unique partial function $f^{\prime}$ such that $f^{\prime}(z)=f(z)$ if $z \neq x$ and $f^{\prime}(x)=y$.

A function $f \in X \stackrel{P}{\Rightarrow} Y$ with Domain $(f)=\left\{x_{1}, \ldots, x_{n}\right\}$ may be written as $\left\{x_{1} \rightarrow f\left(x_{1}\right), \ldots, x_{n} \rightarrow f\left(x_{n}\right)\right\}$. The totally undefined function is written \{\} .

Given a relation $\rightarrow$ (always in an infix notation), $\rightarrow$ is its $n^{\prime}$ th power $(n \geq 0), \rightrightarrows$ is its transitive closure and $\stackrel{*}{\rightarrow}$ is its transitive reflexive closure.

Inductive definitions will be written in the style of the abstract syntax of McCarthy [McC63]; for example binary lists can be defined by List ::=Atom | List List where a list in List may be thought of as an abstract syntax tree. This notation will be extended to encompass sets of partial functions, e.g. $E::=$ Var $\stackrel{P}{\rightarrow} \mathrm{Cl}$ where Var is a countable set of variables. This may also be viewed as defining abstract syntax trees, with at most one subtree of type $\mathrm{Cl}$ for each variable. The notation is similar to VDM notation [Bj申78]. 
The Lambda Calculus

Given predefined disjoint sets $\operatorname{Var}=\{x, y, z, \ldots\}$ and $C$ on $=\{a, b, c, \ldots\}$ of $\underline{\text { variables }}$ and constants respectively, the set of $\lambda$-calculus terms $\operatorname{Lam}=\{M, N, \ldots\}$ is the smallest set such that

(1) Any variable or constant is in Lam.

(2) If $x$ is a variable and $M$ is in Lam then the abstraction $\lambda \times M$ is in Lam.

(3) If $M$ and $N$ are in Lam then the combination $M N$ is also in Lam. $M$ is its rator and $\mathrm{N}$ is its rand.

A term is a value if it is not a combination.

This inductive definition may also be written as follows, using abstract syntax:

Lam ::= Var | Con | $\lambda$ Var Lam | Lam Lam

The free and bound variables $\underline{F V(M)}$ and $\underline{B V(M)}$ of a term $M$ are defined by

(1) $F \vee(a)=\phi ; F \vee(x)=\{x\} ; F \vee(M N)=F \vee(M) \cup F \vee(N) ; F \vee(\lambda \times M)=F \vee(M) \backslash\{x\}$

(2) $B \vee(a)=\varnothing ; B \vee(x)=\varnothing ; B \vee(M N)=B \vee(M) \cup B \vee(N) ; B \vee(\lambda \times M)=B \vee(M) \cup\{x\}$

A term $M$ is closed if $F V(M)=\varnothing$. The substitution prefix $[M / x]$ defines the following operation on Lam: $[M / X] N$ is the result of substituting $M$ for all free occurrences of $x$ in $N$, renaming variables of $N$ as necessary to avoid capturing bound variables as in [Cur58]. Plotkin calls a closed term a program.

The set of contexts $c[$ is defined by

$$
\text { Ctx ::=[] }|C t \times \operatorname{Lam}| \operatorname{Lam} C t \times \mid \lambda \operatorname{Var} C t \times
$$

A context may be viewed as a lambda expression with a "hole" [ ] in it. Noting that a context would be a $\lambda$-expression if [ ] were regarded as a variable, we define $c[M]$ to be the result of "filling the hole" in context $c[$ ] by term $M$.

Now supposing we are given a partial function

$$
\text { Constapply: Con } \times \text { Con } \stackrel{P}{\rightarrow} \text { Closed Values }
$$

we define the reduction relation $>$ on terms by
1. $\lambda \times M>\lambda y[y / x] M$
(if $y \notin F V(M)$ )
$\alpha$ reduction
2. $(\lambda \times M) N>[N / \times] M$
$\beta$ reduction
3. $a b>$ Constapply $(a, b)$ (if this is defined)
$\delta$ reduction
4. $\frac{M>N}{c[M]>c[N]}$
for any context $\mathrm{c}[\mathrm{]}$
reduction in context 
Note that if $M$ is closed and $M>N$ without $\alpha$ reduction then no renaming occurs. Define an outside-in context to be one formed without the rule $C t x::=\lambda$ Var $C t x$, so the "hole" is not in the scope of any $\lambda$. We write $M_{\text {oi }} N$ if $M>N$ by $\beta$ or $\delta$ reduction, possibly in an outside-in context.

A machine-independent definition (from [Plo75]) of call-by-value evaluation is given by the partial function eval $V$ : Programs $\stackrel{P}{\rightarrow}$ Programs defined recursively as follows:

$$
\begin{aligned}
& { }^{\text {eval }} V^{(a)}=a ; \quad \text { eval } V^{(\lambda \times M)=\lambda \times M ;} \\
& \text { eval } V^{(M N)}= \begin{cases}\text { eval } V^{\left(\left[N^{\prime} / \times\right] M^{\prime}\right)} & \text { if eval } V^{(M)}=\lambda \times M^{\prime} \text { and eval } V^{(N)=N^{\prime}} \\
a^{\prime} & \text { if eval } V^{(M)}=a, \text { eval } V^{(N)}=b \text { and }\end{cases} \\
& \text { Constapply }(a, b)=a^{\prime} \text { is defined }
\end{aligned}
$$

The call-by-name evaluation function eval $N$ : Lam $\stackrel{P}{\rightarrow}$ Lam is similarly defined:

$$
\begin{array}{ll}
\operatorname{eval}_{N}(M N)= \begin{cases}{ }^{e v a l} N\left([N / \times] M^{\prime}\right) & \text { if }{ }^{\text {eval }} N^{(M)}=\lambda \times M^{\prime} \\
a^{\prime} & \text { if eval } N(M)=a, \text { eval } N(N)=6 \text { and } \\
& \text { Constapply }(a, b)=a^{\prime} \text { is defined }\end{cases}
\end{array}
$$

It is shown in [Plo75] that these are good definitions of partial functions. Note that both could have been restricted to Programs $\stackrel{P}{\rightarrow}$ Closed values. The following is easily shown.

Lemma 0.1 If $M$ is closed and eval $V^{(M)}$ is defined then $M$ o $_{i}^{*}$ eval $V(M)$; and similarly for eval $N^{(M)}$.

\section{LAMBDA CALCULUS INTERPRETERS}

We first introduce a nondeterministic interpreter which can do arbitrary outside-in reduction sequences and some lemmas about its behaviour. This machine is then restricted to yield two deterministic interpreters CBV and CBN which are proved to perform correctly call-by-value and call-by-name reductions. The terminology and methods of this section owe much to [Plo75].

\section{The OI interpreter}

The $O I$ interpreter is given by a set $\Sigma$ of states and a binary transition relation $\overrightarrow{\mathrm{o} i}$ on $\Sigma$; its data structures and transition rules are summarized in Figure 1 . Auxiliary functions Load: Closed terms $\rightarrow \Sigma$ and Unload: $\Sigma \rightarrow$ Lam are used to initia- 
lize the machine and to read out the $\lambda$-expression denoted by a state.

\section{Data Structures}

To avoid explicit substitutions into $\lambda$-expressions (in the interest of efficiency) an expression will be represented in an interpreter state by a closure of the form $(M, e)$ where $M$ is a term and $e \in E$ is an environment binding its free variables (if any) to other closures. Further, a closure may take the form $\mathrm{cl}_{1} \mathrm{cl}_{2}$, i. e. a combination of two closures. The function Real: $\mathrm{Cl} \rightarrow$ Lam mapping the set $\mathrm{Cl}$ of all closures into the $\lambda$-expressions they denote is given as follows.

In this paper every closure $(M, e)$ will satisfy $F V(M) \subseteq \operatorname{Domain}(e)$, so Real(cl) will always be closed.

$$
\begin{aligned}
\operatorname{Real}\left(\mathrm{cl}_{1} \mathrm{cl}_{2}\right)= & \operatorname{Real}\left(\mathrm{cl}_{1}\right) \operatorname{Real}\left(\mathrm{cl}_{2}\right) \\
\operatorname{Real}((\mathrm{M}, \mathrm{e}))= & {\left.\left[\operatorname{Real}\left(\mathrm{e}\left(x_{1}\right)\right) / x_{1}\right] \ldots\left[\operatorname{Real}\left(\mathrm{e} x_{n}\right)\right) / x_{n}\right] M } \\
& \text { where Domain }(\mathrm{e})=\left\{x_{1}, \ldots, x_{n}\right\}
\end{aligned}
$$

To extend the idea of outside-in contexts to apply to closures we define the set of $\mathrm{Cl}$-contexts by $\mathrm{C}::=[]|\mathrm{C} \mathrm{Cl}| \mathrm{Cl} \mathrm{C}$. The notations $\mathrm{C}[[] \mathrm{Cl}]$ and $\mathrm{C}[\mathrm{cl}[]]$ will have many uses; they denote the $\mathrm{Cl}$-contexts obtained by replacing the single occurrence of [ ] in c by the $\mathrm{Cl}$-contexts [ ] cl and $\mathrm{cl}[$ ], respectively.

A state $\sigma$ in $\Sigma$ may be viewed intuitively as a closure in which a particular subclosure has been identified to be processed next by the interpreter. Formally $\sigma$ is a pair consisting of a $\mathrm{Cl}$-context $\mathrm{c}$ and a closure $\mathrm{cl}$, written in the suggestive notation $\mathrm{c}[\mathrm{cl}]$ (which does not indicate substitution). If $\mathrm{c}=\mathrm{c}_{1}\left[\mathrm{cl}_{1}[]\right]$ then $\mathrm{c}[\mathrm{cl}]$ may also be written $c_{1}\left[\mathrm{cl}_{1}\left[\mathrm{cl}_{2}\right]\right]$, and similarly $c_{1}\left[[] \mathrm{cl}_{2}\left[\mathrm{cl}_{1}\right]\right]$ may be written $\mathrm{c}_{1}\left[\left[\mathrm{Cl}_{1}\right] \mathrm{cl}_{2}\right]$.

Load: Programs $\rightarrow \Sigma$ and Unload: $\Sigma \rightarrow$ Lam are now defined, using \{\} for the initial environment with empty domain. Note that Unload(c[cl]) may be seen as the result of substituting Real(cl) into the context naturally obtained from $c$.

$$
\begin{array}{lll}
\operatorname{Load}\left(\mathrm{M}_{0}\right) & =\left[\left(\mathrm{M}_{0},\{\}\right)\right] \\
\operatorname{Unload}([\mathrm{cl}]) & =\operatorname{Real}(\mathrm{cl}) \\
\operatorname{Unload}\left(\mathrm{c}\left[\mathrm{Cl}_{1}\left[\mathrm{cl}_{2}\right]\right]\right) & =\operatorname{Unload}\left(\mathrm{c}\left[\left[\mathrm{cl}_{1}\right] \mathrm{cl}_{2}\right]\right)=\operatorname{Unload}\left(\mathrm{c}\left[\mathrm{cl}_{1} \mathrm{cl}_{2}\right]\right)
\end{array}
$$

\section{Transition Rules}

Figure 1 contains the transition rules defining $\Rightarrow$ f and repeats the definitions of $\mathrm{Cl}, \mathrm{E}$ etc. in more compact form. 
Data Structures
$\mathrm{Cl}: \mathrm{Cl}::=\operatorname{Lam} \mathrm{E} \mid \mathrm{Cl} \mathrm{Cl}$
Closures
e : E ::= Var $\stackrel{P}{\rightarrow} \mathrm{Cl}$
Environments
$c[]: C \quad::=[]|\mathrm{CCl}| \mathrm{ClC}$
Cl-contexts
$\sigma: \Sigma::=\mathrm{C}[\mathrm{Cl}]$
States

\section{Transition Rules}

1. $c[[(\lambda \times M, e)] c l] \quad \Rightarrow \quad c[(M, e\{c l / \times\})] \quad \beta$ reduction

2. $c\left[[(a, e)]\left(b, e^{\prime}\right)\right] \Rightarrow \quad \Rightarrow \quad c\left[\left(a^{\prime},\{\}\right)\right] \quad \delta$ reduction

(if $\mathrm{a}^{\prime}=$ Constapply $(\mathrm{a}, \mathrm{b})$ is defined)

3. $c[(x e)] \quad \Rightarrow \quad c[e(x)] \quad$ variable expansion

(if $e(x)$ is defined)

4. $c[(M N, e)] \quad \Rightarrow \quad c[(M, e)(N, e)] \quad$ combination

5. $\mathrm{c}\left[\mathrm{cl}_{1} \mathrm{Cl}_{2}\right] \quad \Rightarrow \mathrm{oi}\left[\left[\mathrm{Cl}_{1}\right] \mathrm{cl}_{2}\right] \quad$ scan rator

6. $\left.c\left[\left[\mathrm{cl}_{1}\right] \mathrm{cl}_{2}\right] \quad \Rightarrow \quad \mathrm{oi} \quad \mathrm{cl}_{1} \mathrm{Cl}_{2}\right]$ return from rator

7. $\mathrm{c}\left[\mathrm{Cl}_{1} \mathrm{Cl}_{2}\right] \quad \Rightarrow \quad \mathrm{oi}\left[\mathrm{cl}_{1}\left[\mathrm{cl}_{2}\right]\right] \quad$ scan rand

8. $\mathrm{c}\left[\mathrm{cl}_{1}\left[\mathrm{cl}_{2}\right]\right] \quad \overrightarrow{\mathrm{oi}} \quad \mathrm{c}\left[\mathrm{Cl}_{1} \mathrm{Cl}_{2}\right] \quad$ return from rand

Figure 1. Ol Interpreter.

\section{Example Computation}

Following is an example Ol computation on $M_{0}=(\lambda$ ff 7$)$ square:

$$
\begin{aligned}
& \operatorname{Load}\left(M_{0}\right)=[((\lambda f f 7) \text { square },\{\})] \quad \text { combination } \\
& \Rightarrow \quad[(\lambda f f 7,\{\})(\text { square },\{\})] \quad \text { scan rator } \\
& \overrightarrow{\mathrm{o}} \mathrm{i} \quad[[(\lambda f f 7,\{\}] \text { (square, }\{\})] \quad \beta \text { reduce } \\
& \Rightarrow \quad[(f 7,\{f \rightarrow(\text { square }, \phi)\})] \quad \text { scan rator } \\
& \text { call this e } \\
& \Rightarrow \quad[[(f, e)](7, e)] \quad \text { expand "f" } \\
& \Rightarrow \quad[[(\text { square },\{\})](7, e)] \quad \delta \text { reduce } \\
& \vec{o} i \quad[(49,\{\})]
\end{aligned}
$$


Mathematical Justification

The following provides the mathematical justification of the Ol interpreter; its proof is straightforward but detailed and so appears in the appendix.

Theorem 1.1

a) If $\sigma_{1} \stackrel{*}{\overrightarrow{\mathrm{oi}}} \sigma_{2}$ and Unload $\left(\sigma_{1}\right)$ is closed then Unload $\left(\sigma_{1}\right) \stackrel{\text { ò }}{*} \operatorname{Unload}\left(\sigma_{2}\right)$

b) If $M \stackrel{\partial_{i}^{*}}{*} N$ and $M$ is closed then $\operatorname{Load}(M) \stackrel{\text { o } i}{*} \sigma$ for some $\sigma$ with Unload $(\sigma)=N$.

A similar interpreter has been constructed and proven correct which can do arbitrary reduction sequences (not just outside-in), at the expense of more complexity in handling environments. A deterministic restriction of it could provide an alternative to the $\mathrm{CUCH}$ machine [Böh72], but is omitted due to the difficulties encountered in approximating a renaming interpreter.

\section{Call-by-Value and Call-by-Name Interpreters}

The OI interpreter may be simplified and made deterministic by imposing a consistent ordering on operator and operand evaluation. If the operand is always left unevaluated we have the usual implementation of call-by-name. Figure 2 contains the CBN interpreter; it was obtained from OI by combining transition rules 4 and 5 , dropping $2,6,7,8$ and simplifying closures by omitting $\mathrm{Cl}::=\mathrm{Cl} \mathrm{Cl}$. This machine has been studied by Schmidt [Sch81].

$$
\begin{aligned}
& \text { Define } \text { Last }_{N}: \Sigma \stackrel{P}{\rightarrow} \Sigma \text { and Eval } N \text { : Lam } \stackrel{P}{\rightarrow} \text { Lam by: } \\
& \operatorname{Last}_{N}(\sigma)= \begin{cases}\operatorname{Last}_{N^{\left(\sigma^{\prime}\right)}} & \text { if } \sigma \underset{\mathrm{cbn}}{\Rightarrow} \sigma^{\prime} \text { for some } \sigma^{\prime} ; \\
\sigma & \text { otherwise }\end{cases} \\
& \operatorname{Eval}_{N}\left(M_{0}\right)=\quad \operatorname{Unload}\left(\operatorname{Last}_{N}\left(\operatorname{Load}\left(M_{0}\right)\right)\right)
\end{aligned}
$$

Theorem 1.2

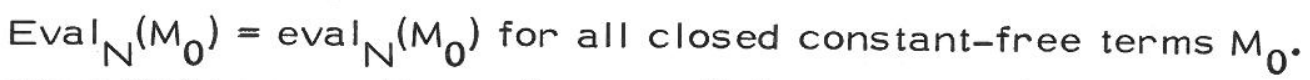

Thus CBN correctly performs call-by-name evaluation. Proof is omitted; a very similar proof for call-by-value is found in the appendix. Constants are omitted for simplicity, and because CBN will not be studied in detail. They could be handled by adding transition rules to evaluate the operand in case the operator value is a constant, plus a $\delta$-reduction rule. A simpler alternative (from [Sch81]) is to require that constant functions be applied in postfix order instead of prefix. 
Data Structures
$\mathrm{Cl}: \mathrm{Cl}::=$ Lam E
Closures
e: $E::=\operatorname{Var} \stackrel{P}{\rightarrow} \mathrm{Cl}$
Environments
$c[]: \mathrm{C}::=[]|\mathrm{C} \mathrm{Cl}| \mathrm{ClC}$
Cl-contexts
$\sigma: \Sigma::=C[\mathrm{Cl}]$
States

Transition Rules
1. $c[[(\lambda \times M, e)] \mathrm{cl}] \underset{\mathrm{cbn}}{\Rightarrow}$
$c[(M, e\{c l / x\})]$
$\beta$ reduction
2. $c[(x, e)]$
$\underset{c b n}{c} \quad c[e(x)]$
variable expansion
(if $e(x)$ is defined)
3. $c[(\mathrm{MN}, \mathrm{e})] \Rightarrow \mathrm{c}[[(\mathrm{M}, \mathrm{e})](\mathrm{N}, \mathrm{e})]$ combination

Figure 2. CBN Interpreter.

\section{Data Structures}
$\mathrm{Cl}: \mathrm{Cl}::=$ Lam E
Closures
e: $E::=\operatorname{Var} \stackrel{P}{\rightarrow} \mathrm{Cl}$
Environments
$c[]: C \quad::=[]|\mathrm{C} \mathrm{Cl}| \mathrm{ClC}$
Cl-contexts
$\sigma: \Sigma \quad::=\mathrm{C}[\mathrm{Cl}]$
States

Transition Rules

1. $c[[(\lambda \times M, e)] c l]-\Rightarrow c[(M, e\{c l / x\})] \quad \beta$ reduction

2. $c\left[[(a, e)]\left(b, e_{1}\right)\right] \Rightarrow c\left[\left(a^{\prime},\{\}\right)\right]$

$\delta$ reduction

(if $\mathrm{a}^{1}=$ Constapply $(\mathrm{a}, \mathrm{b}$ ) is defined)

3. $c[(x, e)] \Rightarrow c[e(x)]$ variable expansion (if $e(x)$ is defined)

4. $c[(\mathrm{MN}, \mathrm{e})] \Rightarrow c[(\mathrm{M}, \mathrm{e})[(\mathrm{N}, \mathrm{e})]]$ combination

5. $\mathrm{c}\left[\mathrm{Cl}_{1}\left[\mathrm{Cl}_{2}\right]\right] \Rightarrow \mathrm{c}\left[\left[\mathrm{Cl}_{1}\right] \mathrm{Cl}_{2}\right]$ scan operator (if $\mathrm{Cl}_{2}=(\mathrm{M}, \mathrm{e})$ where $\mathrm{M}$ is a closed value) 
For call-by-value we evaluate both operator and operand before $\beta$ or $\delta$ reduction. The result is in Figure 3; it was obtained from Ol by combining transition rules 4 and 7 , and applying 8 followed by 5 if operand evaluation produced a value. Rule 6 is omitted since either $\beta$ or $\delta$ reduction must occur after operator evaluation. Define eval $V^{\left(M_{0}\right)}=$ Unload $\left(\right.$ Last $\left(\right.$ Load $\left.\left(M_{0}\right)\right)$ where

$$
\text { Last }(\sigma)= \begin{cases}\text { Last }\left(\sigma^{\prime}\right) & \text { if } \sigma \Rightarrow \sigma^{\prime} \\ \sigma & \text { if } \sigma \not \Rightarrow \sigma^{\prime} \text { for all } \sigma^{\prime} \text { and } \sigma=[\mathrm{cl}] \text { for some cl }\end{cases}
$$

Proof of the following is found in an appendix.

Theorem 1.3

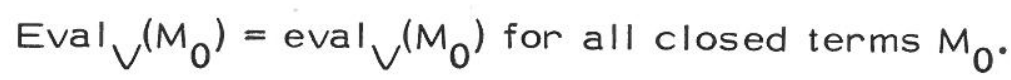

Corollary 1.4

CBV is computationally equivalent to the SECD machine.

Proof Plotkin has shown that SECD computes eval $V$ in [PIo75].

\section{A Useful Property}

In every closure $(M, e)$ which was obtained in the example computation, $M$ was a subexpression of $M_{0}$ or a constant. This is in fact always true.

Lemma 1.5 Suppose $M$ is closed and $\operatorname{Load}\left(M_{0}\right) \stackrel{*}{\stackrel{*}{\Rightarrow}} c[(M, e)]$. Then

a) $\operatorname{Domain}(e) \subseteq B V\left(M_{0}\right)$ and

b) $M$ is a subexpression either of $M_{0}$ or of Constapply(a,b) for some $a, b \in C$ on.

Proof Define "p appears in cll for closures $\mathrm{cl}$ and $\lambda$-expressions or environments $p$ as follows:

i) $M$ and e appear in $(M, e)$

ii) if $p$ appears in $e(x)$ for some $x \in$ Domain(e) then $p$ appears in $(M, e)$

iii) if $\mathrm{p}$ appears in $\mathrm{Cl}_{1}$ or $\mathrm{Cl}_{2}$ then it appears in $\mathrm{Cl}_{1} \mathrm{Cl}_{2}$.

An easy induction on $n$ now verifies that if $\operatorname{Load}\left(M_{0}\right) \underset{0 i}{\Rightarrow} \mathrm{c}[\mathrm{cl}]$ and $p$ appears in cl or any closure in c, then p satisfies a) or b) above.

Lemma 1.5 implies that for each fixed input $M_{0}$ we may regard $O$ l as operating on occurrences of expressions rather than on arbitrary expressions. This useful property follows from the fact that we only do outside-in reductions. It implies that a computer implementation of an OI $\lambda$-calculus machine can manipulate pointers instead of arbitrary $\lambda$-expressions. Incidentally, the SECD machine also has this property. 
The approximations to be developed later will trace occurrences (so all $x^{\prime} s$ are not treated alike, for instance), so we introduce some terminology.

$$
\begin{aligned}
\operatorname{Sub}\left(M_{0}\right)= & \left\{M \mid M \text { is an occurrence of a subexpression in } M_{0}\right\} \\
\text { Subcon }= & \{M \mid M \text { is an occurrence of a subexpression in } N=\text { Constapply }(a, b), \\
& \text { where } a, b \in C \text { on and } N \notin \text { Con }\}
\end{aligned}
$$

The specialization of the OI interpreter to $M_{0}$ is written OI $\left(M_{0}\right)$ and defined in Figure 4. The same concept will also be applied to the call-by-value interpreter CBV yielding its specialized form CBV( $\left.M_{0}\right)$.

Clearly OI $\left(M_{0}\right)$ has a computation $\sigma_{1} \Rightarrow \sigma_{2} \Rightarrow \ldots \Rightarrow \sigma_{n}$ with $\operatorname{Un} \operatorname{load}\left(\sigma_{n}\right)=M$ if and only if $O I$ has a corresponding computation Load $\left(M_{0}\right)=\sigma_{1}{ }^{\prime} \Rightarrow \sigma_{2}{ }^{\prime} \Rightarrow . . . \Rightarrow \sigma_{n}{ }^{\prime}$ with $\operatorname{Unload}\left(\sigma_{n}{ }^{\prime}\right)=M$.

\section{Data Structures}

$$
\begin{aligned}
& \mathrm{Cl}: \mathrm{Cl}::=\operatorname{Lam}\left(\mathrm{M}_{0}\right) \mathrm{E} \mid \mathrm{ClCl} \quad \text { Closures } \\
& \text { e: } \mathrm{E}::=\mathrm{BV}\left(\mathrm{M}_{0}\right) \stackrel{\mathrm{P}}{\rightarrow} \mathrm{Cl} \quad \text { Environments } \\
& c[]: \mathrm{C}::=[]|\mathrm{CCl}| \mathrm{ClC} \quad \text { Cl-contexts } \\
& \sigma: \Sigma \quad::=\mathrm{C}[\mathrm{Cl}] \quad \text { States }
\end{aligned}
$$

\section{Transition Rules}

Identical to those of $\mathrm{OI}$, but regarded as operating on elements of $\operatorname{Lam}\left(M_{0}\right)$.

Figure 4. OI(M $\left.\mathrm{M}_{0}\right)$ Interpreter.

\section{ANALYSIS OF CONTROL FLOW}

Let $M_{0}$ be a given closed $\lambda$-expression without constants, and let $C B \vee\left(M_{0}\right)$ be the $C B V$ interpreter specialized to $M_{0}$. Define

$$
\operatorname{States}\left(M_{0}\right)=\left\{\sigma \mid \operatorname{Load}\left(M_{0}\right) \stackrel{*}{\Rightarrow} \sigma \text { by } \operatorname{CBV}\left(M_{0}\right)\right\}
$$

Note that $\mathrm{CBV}\left(\mathrm{M}_{0}\right)$ can only halt by entering a state of the form $[(\lambda \times M, e)]$, so no "error halts" are possible. It will be shown that a safe description $\delta\left(M_{0}\right)$ may be effectively obtained as follows. 
1. A method will be developed to represent finitely the data structures of $\operatorname{CBV}\left(M_{0}\right)$, yielding a finite lattice $D$ containing computation descriptions $\delta$.

2. For each $\delta \in D$ a representation relation $\stackrel{\delta}{\sim} \Sigma \Sigma \times \Sigma^{\prime}$ will be defined, where $\Sigma^{\prime}$ models the states of $\mathrm{CBV}\left(\mathrm{M}_{0}\right)$. The relation $\sigma \stackrel{\delta}{\sim} \sigma^{\prime}$ will mean that state $\sigma$ is represented by $\sigma^{\prime} \in \Sigma^{\prime}$ in the computation description $\delta$.

3. A continuous simulation function $f: D \rightarrow D$ will be defined satisfying

Lemma 2.1 If $\sigma_{1} \Rightarrow \sigma_{2}$ and $\sigma_{1} \stackrel{\delta}{\sim} \sigma_{1}^{\prime}$ then $\sigma_{2} \stackrel{f(\delta)}{\sim} \sigma_{2}{ }^{\prime}$ for some $\sigma_{2}{ }^{\prime} \in \Sigma^{\prime}$.

4. Safeness will be shown by the following, where $\delta\left(M_{0}\right)$ is the least element of $D$ which describes Load $\left(M_{0}\right)$ and is a fixpoint of $f$.

\section{Theorem 2.2}

If $\sigma \in \operatorname{States}\left(M_{0}\right)$ then $\sigma \stackrel{\delta\left(M_{0}\right)}{\sim} \sigma^{\prime}$ for some $\sigma^{\prime} \in \Sigma^{\prime}$.

5. A linear encoding le of states will be introduced, and a context-free grammar $G\left(M_{0}\right)$ will be constructed from $\delta\left(M_{0}\right)$ will be constructed from $\delta\left(M_{0}\right)$ such that

$$
L\left(G\left(M_{0}\right)\right) \supseteq\left\{l e(\sigma) \mid \sigma \in \operatorname{States}\left(M_{0}\right)\right\}
$$

6. Effective methods will be developed to give "safe" positive answers to the following questions

- Is a subexpression of $M$ never evaluated?

- Will the computation terminate?

- Is States $\left(M_{0}\right)$ finite?

- Is $M$ independent of $N$, for subexpressions $M, N$ of $M_{0}$ ?

\section{TheDescription Lattice D}

The sets of closures, contexts etc. of $C B \vee\left(M_{0}\right)$ are infinite, so for effective approximation it is desirable to represent them finitely. We first develop informal methods for finite representation and then give a mathematical definition of what a representation is. The data structure representations (and more) are summarized in Figure 5.

The sets $E$ and $\mathrm{Cl}$ are infinite, since defined by mutual recursion. However, notice that every value $e(x) \in C l$ comes from a Cl-context as the result of $\beta$-reduction; in fact $C B \vee$ could easily be modified to work with $E::=$ Var $\stackrel{P}{\rightarrow}$ instead of $E::=\operatorname{Var} \stackrel{P}{\rightarrow} C_{1}$. We thus approximate $E$ by $E^{\prime}::=\operatorname{Var} \rightarrow C^{\prime}$ where $C^{\prime}$ is an as-yet-undefined representation of $C$. 
Since $M_{0}$ is constant-free, the closures computed by $C B V\left(M_{0}\right)$ must all lie in $\operatorname{Sub}\left(M_{0}\right) \times E$. We thus approximate closures by $C^{\prime \prime}::=\operatorname{Sub}\left(M_{0}\right) E^{\prime}$. State $\sigma=c[c l]$ will be represented by a pair $\sigma^{\prime}=\left(c^{\prime}, C^{\prime}\right)$, so we define $\Sigma^{\prime}::=C^{\prime} C^{\prime}$.

$\mathrm{Cl-context}$ is also infinite due to its recursive definition. During the $C B \vee\left(M_{0}\right)$ computation, contexts are manipulated "inside out", i.e. from the vicinity of [ ]. The reduction rules remove the innermost closure, and rule 3 has no effect on the closure. Rule 4 "deepens" the $\mathrm{Cl}$-context, changing $\mathrm{C}[]$ to $\mathrm{c}[(\mathrm{M}, \mathrm{e})[\mathrm{]}]$ when processing a combination $(\mathrm{MN}, \mathrm{e})$, and rule 5 changes $\mathrm{c}\left[\mathrm{cl}_{1}[]\right]$ to $\mathrm{c}\left[\left[\mathrm{cl}_{2}\right]\right.$.

Let $\operatorname{Com}\left(M_{0}\right)$ denote the set of occurrences of combinations within $M_{0}$; these will be used for local representations of $C$.

The Cl-contexts appearing in a computation will be represented by two data structures: a set $C^{\prime}$ of local representations, plus a single global retrieval function $c C: C^{\prime} \rightarrow P\left(C I^{\prime} C^{\prime}\right)$ which is used to extract the structure of any $\mathrm{Cl}$-context if given its local representation. A containment $\left(c^{\prime}, c_{1}^{\prime}\right) \in c c\left(c^{\prime}\right)$ indicates that $c^{\prime}$ locally represents a context $c_{1}[\mathrm{cl}[]]$ or $c_{1}[[] \mathrm{cl}]$, where $\mathrm{cl}^{\prime}$ and $c_{1}{ }^{\prime}$ represent $\mathrm{cl}$ and $c_{1}$ respectively. More specifically,

- [ ] locally represents the empty Cl-context。

- $\mathrm{MN}[\mathrm{]}$ locally represents any $\mathrm{Cl}$-context created by a transition $c[(M N, e)] \Rightarrow c[(M, e)[(N, e)]]$. The remaining structure is represented globally by the containment $\left(\left(M, e^{\prime}\right), c^{\prime}\right) \in c c(M N[])$, where $e^{\prime}, c^{\prime}$ represent e, C. $\left(M, e^{\prime}\right)$ represents the operator of the combination $(\mathrm{MN}, \mathrm{e})$. Fur ther, if $\mathrm{MN}[\mathrm{]}$ represents $\mathrm{c}[\mathrm{cl}[]]$ locally, then

- [ ] MN similarly represents (in the local sense) the context created by $\mathrm{c}\left[\mathrm{cl}_{1}\left[\mathrm{cl}_{2}\right]\right] \Rightarrow\left[\left[\mathrm{Cl}_{1}\right] \mathrm{cl}_{2}\right]$. This is globally represented by $\left(\mathrm{cl}_{2}{ }^{\prime}, \mathrm{c}^{\prime}\right) \in \mathrm{cc}\left([\mathrm{MN})\right.$ where $\mathrm{c}^{\prime}$ locally represents $\mathrm{c}[]$ and $\mathrm{cl}_{2}{ }^{\prime}$ represents the reduced form of operand $(\mathrm{N}, \mathrm{e})$.

Consequently we set $C^{\prime}::=[]\left|[] \operatorname{Com}\left(M_{0}\right)\right| \operatorname{Com}\left(M_{0}\right)[]$ and $C C::=C^{1} \rightarrow P\left(C \mid C^{\prime}\right)$.

An entire computation $\sigma_{1} \Rightarrow \sigma_{2} \Rightarrow \ldots$ will be represented by a pair $\delta=(S, c c)$ where $S \subseteq \Sigma^{\prime}$ contains representations of the states (using local context representations) and cc globally represents the structures of all the Cl-contexts.

Let $D::=P(\Sigma) C C$ with the ordering: $\left(S_{1}, c c_{1}\right) \subseteq\left(S_{2}, c c_{2}\right)$ iff $S_{1} \subseteq S_{2}$ and $\forall c^{\prime} \in C^{\prime} c c_{1}\left(c^{\prime}\right) \subseteq c c_{2}\left(c^{\prime}\right)$. D is clearly a complete finite lattice, and is called the description lattice. We write $\perp, T, \sqcup, \cap$ for the least element, greatest element, least upper bound and greatest lower bound, respectively.

The way in which elements of $D$ represent closures, states, etc. is now made precise: 
Definition 2.3 Let $\delta=(S, c c) \in D$. The representation relation

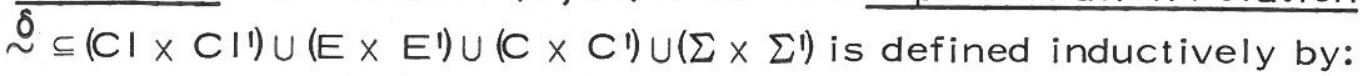

a) $(M, e) \stackrel{\delta}{\sim}\left(M, e^{1}\right)$ if $e^{\sim} \mathrm{e}^{1}$

b) $\mathrm{e} \stackrel{\delta}{\sim} \mathrm{e}^{\prime}$ if $\forall x \in \operatorname{Domain}(\mathrm{e}) \exists\left(\mathrm{cl} \mathrm{I}^{\prime}, \mathrm{c}^{\prime}\right) \in \mathrm{cc}\left(\mathrm{e}^{\prime}(x)\right)$ such that $\mathrm{e}(\mathrm{x}) \stackrel{\delta}{\sim} \mathrm{cl} \mathrm{I}^{\prime}$

c) []$\stackrel{\delta}{\sim}[]$ $\mathrm{c}[\mathrm{cl}[]] \stackrel{\delta}{\sim} \mathrm{MN}[]$ if $\exists\left(\mathrm{cl}, \mathrm{c}^{\prime}\right) \in \mathrm{cc}(\mathrm{MN}[])$ such that $\mathrm{cl} \stackrel{\delta}{\sim} \mathrm{cl}^{\prime}$ and $\mathrm{c} \stackrel{\delta}{\sim} \mathrm{c}^{\prime}$ $\mathrm{c}[[] \mathrm{cl}] \stackrel{\delta}{\sim}[] \mathrm{MN}$ if $\exists\left(\mathrm{cl}, \mathrm{c}^{\prime}\right) \in \mathrm{cc}([] \mathrm{MN})$ such that $\mathrm{cl} \stackrel{\delta}{\sim} \mathrm{cl}^{\prime}$ and $\mathrm{c} \stackrel{\delta}{\sim} \mathrm{c}^{\prime}$ d) $\mathrm{c}[\mathrm{cl}] \stackrel{\delta}{\sim}\left(\mathrm{c}^{\prime}, \mathrm{cl} \mathrm{l}^{\prime}\right)$ if $\mathrm{c} \stackrel{\delta}{\sim} \mathrm{c}^{\prime}, \mathrm{cl} \stackrel{\delta}{\sim} \mathrm{cl}^{\prime}$ and $\left(\mathrm{c}^{\prime}, \mathrm{cl} \mathrm{l}^{\prime}\right) \in \mathrm{s}$.

Note that $\stackrel{\delta}{\sim}$ is monotonic with respect to $\delta: \delta_{1} \sqsubseteq \delta_{2}$ and $\sigma \stackrel{\delta_{1}}{\sim} \sigma^{\prime}$ implies $\sigma \stackrel{\delta_{2}}{\sim} \sigma^{\prime}$.

This technique may be used to approximate the behavior of many algorithms using recursively defined data types, providing an alternative for example to the methods of Jones and Muchnick [JoM81] and Reynolds [Rey68] for simple LISP-like programs. The underlying idea is to represent a recursively-defined structure by the set of program points which contain constructor operations, plus a retrieval function on this set which can be used to retrieve the components put together by a construction. These program points are propagated as descriptions of variables' values along control paths during flow analysis, and selector operations are performed by consulting the retrieval function.

\section{The CBV $\left(M_{0}\right)$ Simulation Function}

It is well known that most forward flow analysis methods essentially carry out an abstract interpretation of the simulated algorithm over a lattice of approximations to states or sets of states. Descriptions of this approach may be found in [ $\operatorname{Sin} 72$ ] and [Cou79].

This approach was used to construct the simulation function $f: D \rightarrow D$ which is defined in Figure 5; the clauses defining $f$ in essence apply the $C B \vee\left(M_{0}\right)$ transition rules to representations of states. Clearly $f$ is monotonic; $D$ is finite, so $f$ is also continuous and so $\delta\left(M_{0}\right)$ is well-defined. Lemma 2. 1 will be proved after an example; we now prove that Theorem 2. 2 follows from Lemma 2. 1.

Proof of Theorem 2.2

Suppose $\operatorname{Load}\left(M_{0}\right)=\sigma_{0} \Rightarrow \sigma_{1} \Rightarrow \ldots \Rightarrow \sigma_{n}$. For $n=0$, $\operatorname{Load}\left(M_{0}\right)=\left([],\left(M_{0},\{\}\right)\right) \stackrel{\delta_{0}}{\sim}\left([],\left(M_{0},\{\}\right)\right)=\sigma_{0}^{\prime}$ where $\delta_{0}=\left(\left\{\sigma_{0}\right\},\{\}\right)$ and \{\} is the empty $\mathrm{Cl}$-context retrieval function. Now $\sigma_{0} \delta\left(M_{0}\right) \sigma_{0}^{\prime}$ follows since $\delta_{0} \sqsubseteq \delta\left(M_{0}\right)$. 
Now suppose inductively that $\sigma_{i} \stackrel{\delta\left(M_{0}\right)}{\sim} \sigma_{i}{ }^{\prime}$. By Lemma 2.1 there exists $\sigma{ }_{i+1}^{1}$ such that $\sigma_{i+1} \stackrel{\delta}{\sim} \sigma_{i+1}^{\prime}$ where $\delta=f\left(\delta\left(M_{0}\right)\right) \sqsubseteq \delta\left(M_{0}\right)$, so $\sigma_{i} \stackrel{\delta\left(M_{0}\right)}{\sim} \sigma_{i+1}^{\prime}$.

\section{Data Structure Descriptions}

$$
\begin{aligned}
& C^{\prime}: C^{\prime}::=\operatorname{Sub}\left(M_{0}\right) E^{\prime} \quad \text { Closures } \\
& \mathrm{e}^{\prime}: \mathrm{E}^{\prime} \quad::=\mathrm{BV}\left(\mathrm{M}_{0}\right) \stackrel{\mathrm{P}}{\rightarrow} \mathrm{C}^{\prime} \quad \text { Environments } \\
& C^{\prime}: C^{\prime} \quad::=[]\left|[] \operatorname{Com}\left(M_{0}\right)\right| \operatorname{Com}\left(M_{0}\right)[] \text { Contexts - local } \\
& \text { descriptions } \\
& \text { Contexts - global } \\
& \text { descriptions } \\
& S \subseteq \Sigma^{\prime} \quad::=C^{\prime} C^{\prime} \quad \text { States } \\
& \delta: D \quad::=P\left(\Sigma^{\prime}\right) C C
\end{aligned}
$$

\section{Simulation Function $f: D \rightarrow D$}

Let $\delta=(S, c c) \in D$. Then $f(\delta)$ is the least pair $\left(S_{1}, c c_{1}\right) \sqsupseteq(S, c c)$ such that the following hold:

1. $\beta$ reduction: if $\left([] N P,\left(\lambda \times M, e^{1}\right)\right) \in S$ and $\left(c l^{\prime}, c^{\prime}\right) \in c c([] N P)$ then $\left(c^{\prime},\left(M, e^{\prime}\{[] N P / x\} \in S_{1}\right.\right.$

2. Variable expansion: if $\left(c^{\prime},\left(x, e^{\prime}\right)\right) \in S$ and $\left(c \prime^{\prime}, c{ }_{1}{ }^{\prime}\right) \in c c\left(e^{\prime}(x)\right)$ then $\left(c^{1}, c^{1}\right) \in S_{1}$

3. Combination: if $\left(\mathrm{C}^{\prime},\left(\mathrm{MN}, \mathrm{e}^{1}\right)\right) \in \mathrm{S}$ then $\left(M N[],\left(N, e^{\prime}\right)\right) \in S_{1}$ and $\left(\left(M, e^{1}\right), C^{\prime}\right) \in C C_{1}(M N[])$

4. Scan operator: if $\left(\mathrm{MN}[], \mathrm{Cl}_{2}^{\prime}\right) \in S$ where $\mathrm{Cl}_{2}^{\prime}=\left(P, \mathrm{e}^{\prime}\right)$ for some closed value $P$ and $\left(\mathrm{cl}_{1}{ }^{\prime}, \mathrm{c}^{\prime}\right) \in \mathrm{cc}(\mathrm{MN}[])$

then $\left([] \mathrm{MN}, \mathrm{Cl}_{1}{ }^{\prime}\right) \in \mathrm{S}_{1}$ and $\left(\mathrm{cl}_{2}{ }^{\prime}, \mathrm{c}^{\prime}\right) \in \mathrm{cc}_{1}([] \mathrm{MN})$

\section{Control Flow Description $\delta\left(M_{0}\right) \in D$}

This is the least solution to the equation $\delta=f(\delta) \sqcup$ Load' $^{\prime}\left(M_{0}\right)$, where

$$
\operatorname{Load}^{\prime}\left(M_{0}\right)=\left(\left\{\left([],\left(M_{0},\{\}\right)\right)\right\},\{\}\right) \text { describes }\left\{\operatorname{Lad}\left(M_{0}\right)\right\} \text {. }
$$

Figure 5. Simulation Function and Description Lattice.

\section{An Example}

Let $M_{0}=A B=(\lambda x x x)(\lambda y y)$. The reduction sequence $M_{0}>(\lambda y y)(\lambda y y) \geq \lambda y y$ as computed by $\operatorname{CBV}\left(M_{0}\right)$ and as represented by $\hat{\delta}\left(M_{0}\right)=(S, c c)$ are as in FIgure 6 . 


\begin{tabular}{|c|c|c|c|}
\hline \multicolumn{2}{|c|}{ CBV $\left(M_{0}\right)$ Computation } & \multicolumn{2}{|r|}{ Approximation } \\
\hline State & Action & $\underline{\underline{s}}$ & $\underline{\mathrm{cC}}$ \\
\hline$[(\mathrm{AB},\{\})]$ & scan operand & $([],(A B,\{\}))$ & \\
\hline$\Rightarrow[(A,\{\})[(B,\{\})]]$ & scan operator & $(A B[],(B,\{\}))$ & $((\mathrm{A},\{\}),[]) \in \mathrm{cc}(\mathrm{AB}[\mathrm{]})$ \\
\hline$\Rightarrow[[(\mathrm{A},\{\})](\mathrm{B},\{\})]$ & $\beta$ reduce & $([] \mathrm{AB},(\mathrm{A},\{\}))$ & $((\mathrm{B},\{\}),[]) \in \mathrm{cc}([] \mathrm{AB})$ \\
\hline$\Rightarrow[(x x,\{x \rightarrow(B,\{\})\})]$ & scan operand & $([],(x x,\{x \rightarrow[$ & $A B\} 川$ \\
\hline call this e & & call th & is $e^{\prime}$ \\
\hline$\Rightarrow[(a, e)[(x, e)]]$ & expand $x$ & $\left(x \times[],\left(x, \mathrm{e}^{\prime}\right)\right)$ & \\
\hline$\Rightarrow[(x, e)[(B,\{\})]]$ & scan operator & $(x \times[],(B,\{\}))$ & $\left(\left(x, e^{\prime}\right),[]\right) \in \operatorname{cc}(x x[])$ \\
\hline$\Rightarrow[[(x, e)](B,\{\})]$ & expand $x$ & $\left([] \times x,\left(x, e^{\prime}\right)\right)$ & $((\mathrm{B},\{\}),[]) \in \mathrm{cc}([] \times x)$ \\
\hline$\Rightarrow[[(\mathrm{B}, \varnothing)](\mathrm{B},\{\})]$ & $\beta$ reduce & $([] \times x,(B,\{\}))$ & \\
\hline$\Rightarrow[(y,\{y \rightarrow(B,\{\})\})]$ & expand y & $([],(y,\{y \rightarrow[]$ & $(x\}))$ \\
\hline$\Rightarrow[(\mathrm{B},\{\})]$ & & $([],(B,\{\}))$ & \\
\hline
\end{tabular}

Figure 6. $\mathrm{CBV}\left(\mathrm{M}_{0}\right)$ Computation and Approximation.

Proof of Lemma 2. 1

Suppose $\sigma_{1} \Rightarrow \sigma_{2}$ and $\sigma_{1} \stackrel{\delta}{\sim} \sigma_{1}{ }^{\prime}$ where $\delta=(S, c c)$.

Case 1. $c[[\lambda \times M, e)] c l]=\sigma_{1} \Rightarrow \sigma_{2}=c[(M, e\{c l / x\})]$.

Let $\sigma \stackrel{\delta}{\sim}\left([] N P,\left(\lambda \times M, e^{1}\right)\right)$. Then $\exists c^{\prime}, c l^{\prime}$ such that $\mathrm{e} \stackrel{\delta}{\sim} \mathrm{e}^{\prime}, c \stackrel{\delta}{\sim} c^{\prime}, c \mid \stackrel{\delta}{\sim} c^{\prime}$ and $\left(c^{\prime}, e^{\prime}\right) \in \operatorname{cc}([] N P)$. By definition of $\left.f, \sigma_{2}^{\prime}=\left(c^{\prime}, M, e^{\prime}\{[] N P / x\}\right)\right) \in S_{1}$. To show $\sigma_{2} \stackrel{f(\delta)}{\sim} \sigma_{2}^{\prime}$ we need only establish e $\{c l / x\} \stackrel{f(\delta)}{\sim} e^{\prime}\{[] N P / x\}$. This follows from the definition of $\stackrel{\delta}{\sim}$ and the facts that $\mathrm{e} \stackrel{\delta}{\sim} \mathrm{e}^{\prime}$ and $\left(\mathrm{cl}^{\prime}, \mathrm{c}^{\prime}\right) \in \operatorname{cc}([] \mathrm{NP})$.

Case 2. $\mathrm{c}[(\mathrm{x}, \mathrm{e})]=\sigma_{1} \Rightarrow \sigma_{2}=\mathrm{c}[\mathrm{e}(\mathrm{x})]$.

If $\sigma \underset{1}{\stackrel{\delta}{\sim}\left(c^{\prime},\left(x, e^{\prime}\right)\right) \text { then } \sigma_{2} \underset{\sim}{\sim}(\delta)}\left(c^{\prime}, e^{\prime}(x)\right)$ by the definitions of $e \stackrel{\delta}{\sim} e^{\prime}$ and $f$.

Case 3. $c[(M N, e)]=\sigma_{1} \Rightarrow \sigma_{2}=c[(M, e)[(N, e)]]$.

Let $\sigma_{1} \stackrel{\delta}{\sim}\left(c^{\prime},\left(M N, e^{\prime}\right)\right)$. By definition of $f, \sigma_{2}^{\prime}=\left(M N[],\left(N, e^{\prime}\right)\right) \in S_{1}$ and $\left(\left(M, e^{1}\right), c^{\prime}\right) \in c_{1}(M N[])$. Now $(M, e) \stackrel{\delta}{\sim}\left(M, e^{\prime}\right)$ so $c[(M, e)[]] \stackrel{\delta}{\sim} M N[]$. This and $(N, e) \stackrel{\delta}{\sim}\left(N, e^{\prime}\right)$ implies $\sigma_{2}{ }^{f(\delta)} \sigma_{2}{ }^{\prime}$. 
Case 4. $\quad c\left[\mathrm{Cl}_{1}\left[\mathrm{cl}_{2}\right]\right]=\sigma_{1} \Rightarrow \sigma_{2}=\mathrm{c}\left[\left[\mathrm{cl}_{1}\right] \mathrm{cl}_{2}\right]$ with $\mathrm{cl}_{2}$ suitably restricted.

Let $\sigma_{1} \stackrel{\delta}{\sim}\left(\mathrm{MN}[], \mathrm{cl}_{2}{ }^{\prime}\right)$. Then $\exists \mathrm{c}^{\prime}, \mathrm{cl}_{1}{ }^{\prime}$, such that $\mathrm{cl}_{2} \stackrel{\delta}{\sim} \mathrm{cl}_{2}{ }^{\prime}, \mathrm{c} \stackrel{\delta}{\sim} \mathrm{cl}^{\prime}, \mathrm{cl}_{1} \stackrel{\delta}{\sim} \mathrm{cl}_{1}{ }^{\prime}$ and $\left(\mathrm{cl}_{1}{ }^{\prime}, \mathrm{c}^{\prime}\right) \in \mathrm{cc}(\mathrm{MN}[])$. By definition of $\mathrm{f}, \sigma_{2}{ }^{\prime}=\left([] \mathrm{MN}, \mathrm{cl}_{1}{ }^{\prime}\right) \in \mathrm{s}_{1}$ and

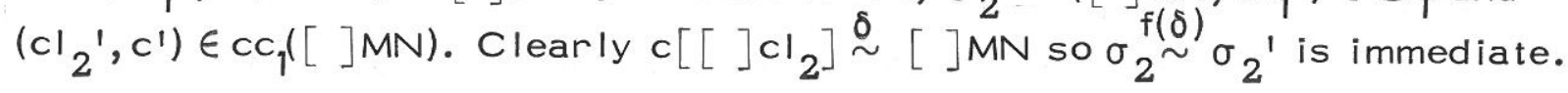

\section{A Context-free Approximation to States $\left(M_{0}\right)$}

First we define a way to encode states, etc. as linear strings of symbols. A Cl-context will be written linearly as $\left(i_{1}, c l_{1}\right) \ldots\left(i_{n}, c l_{n}\right)$ where each $i_{j}$ is 1 if $\mathrm{Cl}_{\mathrm{j}}$ is in operator position and 2 if in operand position. For example $c=\left(\mathrm{cl}_{1}\left([] \mathrm{cl}_{2}\right)\right) \mathrm{cl}_{3}$ becomes $\left(2, \mathrm{cl}_{2}\right)\left(1, \mathrm{cl}_{1}\right)\left(2, \mathrm{cl}_{3}\right)$. This would be suitable for computer implementation since the $O I$ and $C B V$ transition rules in effect treat such a string as a stack with the top at the left end. An environment e will be encoded as $\left\{x_{1} \rightarrow e\left(x_{1}\right), \ldots, x_{n} \rightarrow e\left(x_{n}\right)\right\}$ where Domain $(e)=\left\{x_{1}, \ldots, x_{n}\right\}$ and $x_{1}<x_{2}<\ldots<x_{n}$ relative to some arbitrary fixed order relation on Var.

The linear encoding function le: $C I \cup E \cup C \cup \Sigma \rightarrow A^{*}$ is defined as follows, where $A$ is the alphabet $A=\operatorname{Var} \cup\{(),,\{\},,[],, \rightarrow, 1,2\} \cup\{$,$\} .$

$$
\begin{array}{ll}
\operatorname{le}((M, e))= & (M, \operatorname{le}(e)) \\
\operatorname{le}(e) & =\left\{x_{1} \rightarrow \operatorname{le}\left(e\left(x_{1}\right)\right), \ldots, x_{n} \rightarrow \operatorname{le}\left(e\left(x_{n}\right)\right)\right\} \\
& \text { where Domain }(e)=\left\{x_{1}, \ldots, x_{n}\right\} \text { and } x_{1}<\ldots<x_{n} \\
\operatorname{le}([]) & \epsilon \text { (the empty string) } \\
\operatorname{le}(\mathrm{cl} \mathrm{c}) & \operatorname{le}(c)(1, \operatorname{le}(c \mid)) \\
\operatorname{le}(\mathrm{c} \mathrm{cl}) & =\operatorname{le}(c)(2, \mid \mathrm{le}(\mathrm{cl})) \\
\operatorname{le}(\mathrm{c}[\mathrm{cl}]) & =\operatorname{le}(c)[\operatorname{le}(\mathrm{cl})]
\end{array}
$$

Definition 2.4 Let $\delta=(S, C c)$ be the control flow description of $\operatorname{CBV}\left(M_{0}\right)$. The context-free grammar $G\left(M_{0}\right)$ is defined in Figure 7 .

An example derivation from Figure 5 is

$$
\begin{aligned}
S & \Rightarrow \overline{[]}\left[\left(\overline{x x, \mathrm{e}^{1}}\right)\right] \stackrel{*}{\Rightarrow}\left[\left(x x, \overline{\mathrm{e}^{1}}\right)\right] \\
& \Rightarrow[(x x,\{x \rightarrow(\overline{\mathrm{B},\{\}})\})] \Rightarrow[(x x,\{x \rightarrow(\lambda y y,\{\})\})]
\end{aligned}
$$




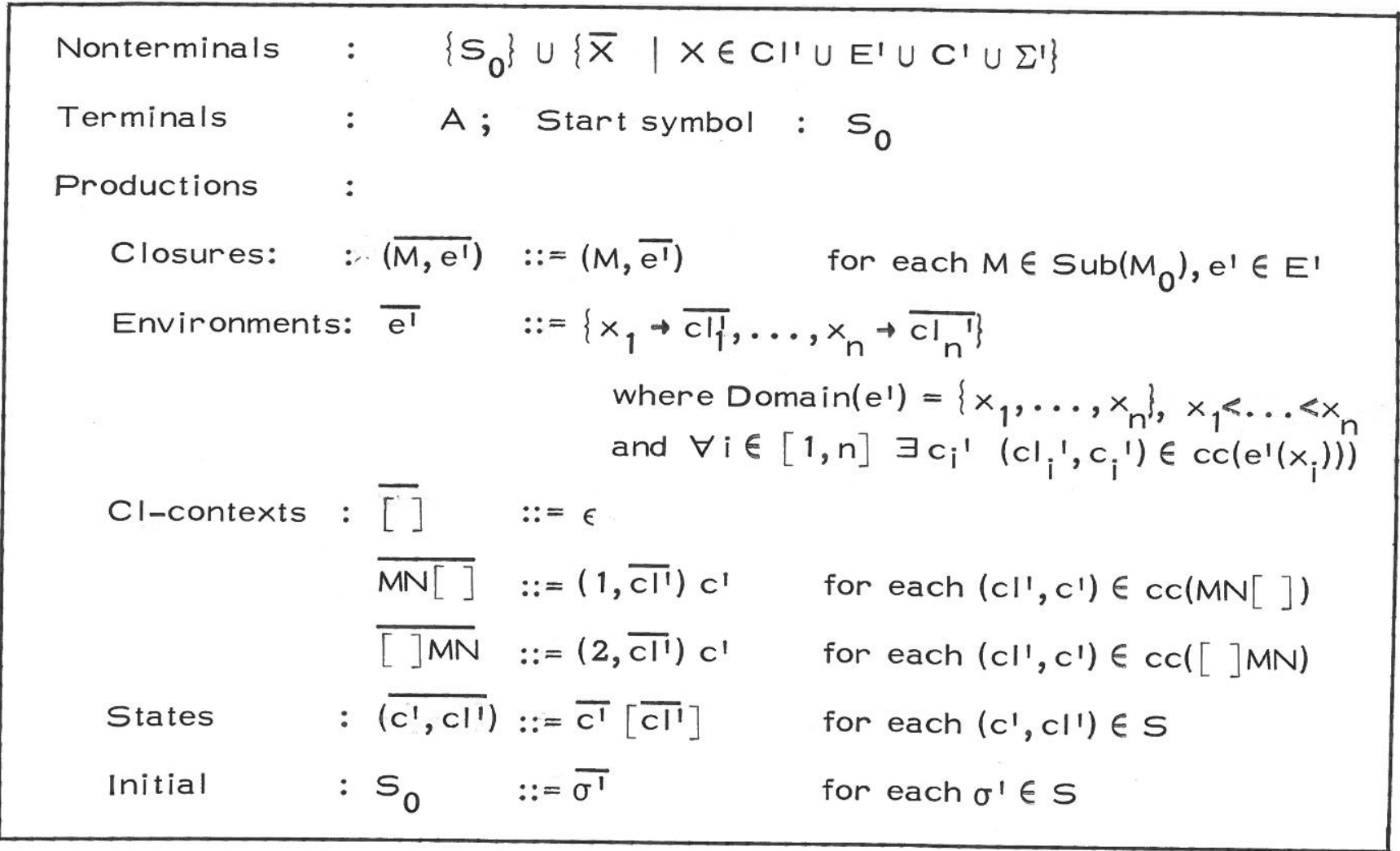

Figure 7. Context-free Grammar $G\left(M_{0}\right)$ Approximating States $\left(M_{0}\right)$.

For any nonterminal $\bar{X}$ let $L(\bar{x})=\left\{x \in A^{*} \mid \bar{X} \stackrel{*}{\Rightarrow} \times\right\}$.

\section{Theorem 2.5}

Let $M_{0}$ be a closed constant-free $\lambda$-expression and $\delta$ its control flow description. For each $x^{\prime} \in X^{\prime}$ where $X=C I, E, C$ or $\Sigma$ :

$$
L\left(\overline{x^{\prime}}\right)=\left\{|\mathrm{e}(x)| \times \stackrel{\delta}{\sim} x^{\prime} \text { and } x \in \times\right\}
$$

Proof is a straightforward induction on definition 2.3 of $x \stackrel{\delta}{\sim} x^{\prime}$.

\section{Corollary 2.6}

$$
L\left(G\left(M_{0}\right)\right) \supseteq\left\{|e(\sigma)| \sigma \in S \operatorname{tates}\left(M_{0}\right)\right\} .
$$


Applications

Let a "safe positive reply" $P$ to a question whose answer is $Q$ be one such that $P$ logically implies $Q$. Given $N \in \operatorname{Sub}\left(M_{0}\right)$ and $(M, e) \in C l$ define $(M, e)$ to depend on $N$ if either $M=N$ or for some $x \in F V(M), e(x)$ depends on $N$. We say that $M$ depends on $N$ for $M, N \in \operatorname{Sub}\left(M_{0}\right)$ if $S$ contains a state $c[(M, e)]$ with $(M, e)$ dependent on $\mathrm{N}$.

\section{Theorem 2.7}

There is a decidable method to obtain nontrivial safe positive replies to the following questions about a closed constant-free $\lambda$-expression $M_{0}$ :

1. Is evaluation of $M \in \operatorname{Sub}\left(M_{0}\right)$ never attempted? (Meaning: does States $\left(M_{0}\right)$ contain no state $c[(M, e)]$ ?).

2. Will the computation terminate?

3. Will the computation fail to terminate?

4. Is States $\left(M_{0}\right)$ finite?

5. Is $M$ independent of $N\left(\right.$ given $\left.M, N \in \operatorname{Sub}\left(M_{0}\right)\right)$ ?

Proof is by showing how to analyze the structure of $\delta(M)=\delta=(S, c c)$. Question 1 is simple: if $S$ contains no pair $\left(C^{\prime},\left(M, e^{\prime}\right)\right)$ then $S$ tates $\left(M_{0}\right)$ contains no state $c[(M, e)]$ by Theorem 2.2.

Define the flowchart of $M$ to have nodes in $\Sigma^{\prime}$ and an edge $\sigma_{1}^{\prime} \Rightarrow \sigma_{2}^{\prime}$ just in case $\sigma_{2}^{\prime} \in S_{1}$ where $f\left(\left\{\sigma_{1}{ }^{\prime}\right\}, c c\right)=\left(S_{1}, c c\right)$. It is easy to see that if $\sigma_{1} \underset{\delta}{\delta} \sigma_{1}^{\prime}$ then $\sigma_{1} \Rightarrow \sigma_{2}$ by CBV $\left(M_{0}\right)$ implies $\sigma_{1}^{\prime} \Rightarrow \sigma_{2}^{\prime}$ in the flowchart for some $\sigma_{2}^{\prime}$ with $\sigma_{2} \stackrel{\delta}{\sim} \sigma_{2}^{\prime}$. Letting the $\operatorname{CBV}\left(M_{0}\right)$ computation be $\operatorname{Load}\left(M_{0}\right)=\sigma_{0} \Rightarrow \sigma_{1} \Rightarrow \ldots$, there exists a path $\sigma_{0}{ }^{\prime} \Rightarrow \sigma_{1}{ }^{\prime} \Rightarrow \ldots$ where each $\sigma_{i} \stackrel{\delta}{\sim} \sigma_{i}{ }^{\prime}$ for $n \geq 0$ and $\sigma_{0}{ }^{\prime}=\left([],\left(M_{0},\{\}\right)\right)$.

If the computation is infinite there must exist $\sigma^{\prime}$ such that $\sigma_{0}{ }^{*} \Rightarrow \sigma^{\prime} \stackrel{+}{\Rightarrow} \sigma^{\prime}$, since $\Sigma^{\prime}$ is finite. This condition is certainly decidable, and its falsity implies the computation is finite. Question 3 may be answered "yes" if there is no path $\sigma_{0}{ }^{*} \Rightarrow \sigma^{\prime}$ where $\sigma^{\prime} \not \nexists \sigma_{1}^{\prime}$ for all $\sigma_{1}{ }^{\prime}$. Note that safe answers to questions 2 and 3 can both be "no".

Question 4 can be answered simply by constructing $G\left(M_{0}\right)$ and testing $L\left(G\left(M_{0}\right)\right.$ ) for finiteness; by Corollary 2.6 a positive answer implies $S$ tates $\left(M_{0}\right)$ is finite. It is well known that finiteness of context-free languages is decidable.

For question 5 , define "Cl' depends on $\mathrm{N}$ " for $\mathrm{cl} \in \mathrm{Cl}$ ' by 
a) $\left(M, e^{\prime}\right)$ depends on $M$ for any $e^{\prime} \in E^{\prime}$

b) $\left(M, e^{\prime}\right)$ depends on $N$ if there exist $x \in F V(M)$ and $\left(c l^{\prime}, c^{\prime}\right) \in \operatorname{cc}\left(e^{\prime}(x)\right)$ such that $\mathrm{cll}^{\prime}$ depends on $\mathrm{N}$.

It is easily seen that if $(M, e)$ depends on $N$ and $(M, e) \stackrel{\delta}{\sim}\left(M, e^{\prime}\right)$ then $\left(M, e^{\prime}\right)$ depends on $N$. The set of all pairs $\left(M, C I^{\prime}\right)$ such that $\mathrm{Cl}^{\prime}$ depends on $M$ is clearly effectively computable. Finally, $M$ is independent of $N$ if there exists no $\left(c,\left(M, e^{\prime}\right)\right) \in S$ with $\left(M, e^{\prime}\right)$ dependent on $N$.

\section{ANALYSIS OF DATA AND CONTROL FLOW}

A method will now be given to obtain a safe description of States $\left(M_{0}\right)$ where $M_{0}$ is an arbitrary $\lambda$-expression. The method involves the use of an auxiliary lattice to approximate sets of constants. The development is otherwise quite parallel to the previous one, so only the essential details are given. For the method to succeed finitely, however, we need the following reasonable

Assumption Subcon is finite.

\section{Approximation of Constants}

Since the set of constants is infinite and our descriptions of $S \operatorname{tates}\left(M_{0}\right)$ are finite, it is necessary to find a way to finitely represent unbounded sets of constants. This is traditionally done in flow analysis by use of a complete approximation lattice $L$ whose elements represent sets of constants via an abstraction function abs: $P(C$ on $) \rightarrow L$. For example a suitable $L$ for "constant propagation" would be the one in Figure 8. Constant propagation allows the recognition of subexpressions which always evaluate to the same value, and determination of that value.

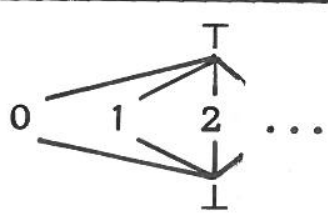

abs: $P(\{0,1,2, \ldots\}) \rightarrow L$

$\operatorname{abs}(A)=\underline{\text { if }} A=\varnothing \underline{\text { then }} \perp$ else if $A=\{a\} \underline{\text { then }}$ a else $T$

Figure 8. A Simple Approximation Lattice L. 
Not all abstraction functions and lattices are suitable for flow analysis. An appropriate and useful restriction due to Cousot is that there exist a concretization function conc: $L \Rightarrow P(C o n)$ such that (abs, conc) are a pair of adjoined functions. Letting $\sqsubseteq$ be the ordering on $L$ this means that

$$
\forall A \subseteq \text { Con } \quad \forall I \in L \quad A \subseteq \operatorname{conc}(1) \text { iff } \operatorname{abs}(A) \sqsubseteq 1
$$

Motivation of this definition and useful mathematical properties may be found in [Cou79]. A suitable concretization function for constant propagation is: $\operatorname{conc}(\perp)=\varnothing$, $\operatorname{conc}(a)=\{a\}, \operatorname{conc}(T)=$ Con.

In order to effectively obtain finite descriptions we also require that $L$ have the finite chain property, i.e. that there exist no infinite properly increasing chains. Note that the example is infinite but has the finite chain property.

\section{The Description Lattice Dcon}

This extends the $D$ lattice used before. Figure 9 contains Dcon and the simulation function $f_{\text {con }}$. Note that $E^{\prime}, C^{\prime}$ and $\Sigma^{\prime}$ are as in Figure 5 but that $C^{\prime}$, CC and Dcon are more elaborate.

By Lemma 1.5 an achievable closure $\left(M\right.$, e) must have $M \in \operatorname{Lam}\left(M_{0}\right)=$ $\operatorname{Sub}\left(M_{0}\right) \cup$ Subcon $\cup$ Con. In Dcon we represent a closure by either $I \in L$ describing a set of constant values, or a pair $\left(M, e^{\prime}\right)$ with $M \in \operatorname{Sub}\left(M_{0}\right) \cup \operatorname{Subcon}$.

We cannot use Dcon $::=P\left(\Sigma^{\prime}\right) C C$ since $P\left(\Sigma^{\prime}\right)=P\left(C^{\prime} C I^{\prime}\right)$ may not possess the finite chain property (as in Figure 8 ). This problem is resolved by merging a $\mathrm{n}$ set $\left\{\left(c^{\prime}, I_{1}\right), \ldots,\left(c^{\prime}, I_{n}\right)\right\} \subseteq C^{\prime} \times C_{i}^{\prime}$ with $I_{1}, \ldots, I_{n}^{\prime} \in L$ into the single pair $\left(c^{\prime},{\left.\underset{i=1}{L} I_{i}\right) .}_{P\left(\Sigma^{\prime}\right) \text { is replaced by }}\right.$

$$
C^{\prime} \otimes C^{\prime}=\left\{x \subseteq C^{\prime} \times C I^{\prime} \mid\left(c^{\prime}, 1_{1}\right),\left(c^{\prime}, I_{2}\right) \in C^{\prime} \times L \text { implies } 1_{1}=I_{2}\right\}
$$

Clearly $C^{\prime} \otimes C^{\prime}$ has no infinite ascending chains. We now define Dcon $::=\left(C^{\prime} \otimes C^{\prime}\right) C C$. An order relation $\leqq$ can now be imposed on $C^{\prime} \otimes C^{\prime}$ to make Dcon a complete lattice, as follows. The following function is easily seen to be an isomorphism:

$$
\begin{aligned}
& g: C^{\prime} \otimes C^{\prime} \rightarrow P\left(C^{\prime} \times\left(\left(\operatorname{Sub}\left(M_{0}\right) \cup \text { Subcon }\right) \times E\right) \times\left(C^{\prime} \stackrel{P}{\rightarrow} L\right)\right. \\
& g(\times)=\left(\times \cap\left(C^{\prime} \times\left(\left(\operatorname{Sub}\left(M_{0}\right) \cup \text { Subcon }\right) \times E\right)\right), \lambda C \text { if }(c, I) \in \times \underline{\text { then }} \text { l else undefined }\right)
\end{aligned}
$$

Informally, if $g(X)=(Y, h)$ then $Y$ consists of those pairs $\left(c^{\prime}, c^{\prime}\right)$ where $c l^{\prime}$ is not in $L$, and $h$ maps $c^{\prime}$ to $I$ iff $\left(c^{\prime}, 1\right) \in X$ and $l \in L$. The range of $g$ is certainly a complete lattice with $(Y, h) \leq\left(Y^{\prime}, h^{\prime}\right)$ iff $Y \subseteq Y^{\prime}$ and $\forall c \in C^{\prime}\left(h(c) \subseteq h\left(c^{\prime}\right)\right.$. Now define $X_{1} \sqsubseteq X_{2}$ iff $g\left(X_{1}\right) \leq g\left(X_{2}\right)$, making $C^{\prime} \otimes C^{\prime}$ into a complete lattice. 
Note that $\left(c^{\prime}, c^{\prime}\right) \in \times$ and $\left\{\left(c^{\prime}, c^{\prime}\right)\right\} \subseteq \times$ are both meaningful. Both are used in Figure 9.

Similarly the set of global context descriptions $C C::=C^{\prime} \rightarrow C^{\prime} \otimes C^{\prime}$ is a complete lattice, with $C^{\prime} \otimes C^{\prime}$ defined symmetrically to $C^{\prime} \otimes C^{\prime}$. It should now be evident that Dcon is a complete lattice with the finite chain property.

\section{The Simulation Function}

This function $f_{\text {con }}$ is constructed in the same way as $f$, to simulate the effect of a $\operatorname{CBV}\left(M_{0}\right)$ transition $\sigma_{1} \Rightarrow \sigma_{2}$ in terms of the data structure $\delta$ representing $\sigma_{1}$. Constants can either be computed or original subexpressions of $M_{0}$; thus we add a rule to convert closure (con, e) into its representation abs con\} in L. For $\delta$ reduction we must map backwards from $L$ to $C$ on and then forward into $L$ again. This is done with the aid of Conap: $L \times L \rightarrow P(C o n)$ and Lamap: $L \times L \rightarrow P(L a m)$ defined by:

$$
\begin{array}{r}
\operatorname{Conap}\left(I_{1}, I_{2}\right)=\text { Con } \cap \text { Back, } \operatorname{Lamap}\left(I_{1}, I_{2}\right)=\text { Subcon } \cap \text { Back } \\
\operatorname{Back}\left(I_{1}, I_{2}\right)=\left\{a^{\prime} \mid \exists a \in \operatorname{conc}\left(I_{1}\right), b \in \operatorname{conc}\left(I_{2}\right)\right. \text { such that } \\
\left.a^{\prime}=\text { Constapply }(a, b) \text { is defined }\right\}
\end{array}
$$

\section{Fur ther Development}

It seems clear that the steps taken earlier for control flow analysis can now be paralleled: a representation relation $\sigma \stackrel{\delta}{\sim} \sigma^{\prime}$ could be defined, safeness proved, and a context-free grammar generating a superset of $\left\{l e(\sigma) \mid \sigma \in S\right.$ tates $\left.\left(M_{0}\right)\right\}$ could be constructed. We do not do this for brevity and because no new ideas are involved.

The CBV $\left(M_{0}\right)$ interpreter may perform an "error halt" if $M_{0}$ contains constants; a state $c\left[[(a, e)]\left(b, e_{1}\right)\right]$ with $a \in$ Con causes nonstandard termination unless $b \in C$ on and Constapply $(a, b)$ is defined. Taking this into account it appears straightforward to extend the methods of Theorem 2.7 to obtain effectively safe positive replies to the five questions stated there, plus:

6. Is the computation free of error halts?

7. Is a given variable occurrence bound only to a single constant value? (If so, its value can be obtained.) 
Data Structure Descriptions

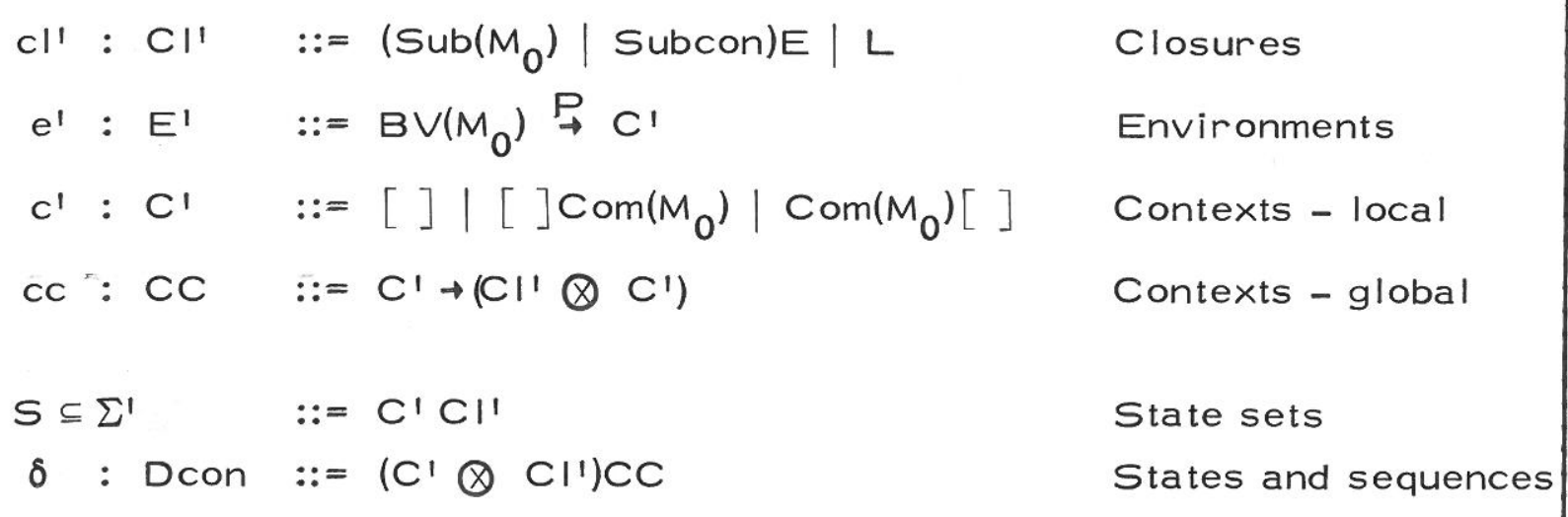

Simulation Function $\mathrm{f}_{\text {con }}$ : Dcon $\rightarrow$ Dcon

Let $\delta=(S, c c) \in$ Dcon. Then $f_{c o n}(\delta)$ is the least pair $\left(S_{1}, c c\right)$ satisfying:

1. $\beta$ reduction: if $\left([] N P,\left(\lambda \times M, e^{\prime}\right)\right) \in S$ and $\left(c^{\prime}, c^{\prime}\right) \in c c([] N P)$

then $\left(c^{\prime},(M, e\{[] N P / \times\}) \in S_{1}\right.$

2. $\delta$ reduction: if $\left([] N P, I_{1}\right) \in S_{1}$ and $\left(I_{2}, c^{\prime}\right) \in c c_{1}([] N P)$

then a) $\left\{\left(c^{\prime}, \operatorname{abs}\left(\operatorname{Conap}\left(I_{1}, I_{2}\right)\right)\right)\right\} \subseteq S_{1}$

b) $\left(c^{\prime},(M,\{\})\right) \in S_{1}$ for each $M \in \operatorname{Lamap}\left({ }_{1}, I_{2}\right)$

3. Constant representation: if $\left(c^{\prime},(c o n, e)\right) \in S$ then $\left(c^{\prime}\right.$, abs $\left.\{c o n\}\right) \sqsubseteq S_{1}$

4. Variable expansion: if $\left(c^{\prime},\left(x, e^{\prime}\right)\right) \in S$ and $\left(c l^{\prime}, c{ }_{1}^{\prime}\right) \in c c\left(e^{\prime}(x)\right)$ then $\left(c^{\prime}, c^{\prime}\right) \in S_{1}$

5. Combination: if $\left(c^{\prime},\left(M N, e^{\prime}\right)\right) \in S$ then $\left(M N[],\left(N, e^{\prime}\right)\right) \in S_{1}$ and $\left(\left(M, e^{\prime}\right), c^{\prime}\right) \in c_{1}(M N[])$

6. Scan operator: if $\left(\mathrm{MN}[], \mathrm{Cl}_{2}^{\prime}\right) \in S$ where $\mathrm{Cl}_{2}^{\prime}=\left(P, \mathrm{e}^{\prime}\right)$ for some closed value $P$, and $\left(\mathrm{cl}_{1}{ }^{1}, \mathrm{c}^{\prime}\right) \in \mathrm{cc}(\mathrm{MN}[])$

then $\left([] \mathrm{MN}, \mathrm{Cl}_{1}{ }^{\prime}\right) \in \mathrm{S}_{1}$ and $\left(\mathrm{cl}_{2}{ }^{\prime}, \mathrm{c}^{\prime}\right) \in \mathrm{cc}{ }_{1}([] \mathrm{MN})$

\section{Data and Control Flow Description}

$\delta\left(M_{0}\right)$ is the least solution to the equation $\delta=f(\delta) \sqcup \operatorname{Load}^{\prime}\left(M_{0}\right)$

Figure 9. Approximate Description of Data and Control Flow. 
It has been shown that safe answers may be effectively obtained to a variety of questions about call-by-value reduction sequences including finiteness, termination, freedom from errors, and independence of subexpressions. The methods used are clearly applicable to call-by-name; further since abstract interpretation does not depend on determinism it seems likely that the Ol interpreter could be similarly analyzed, giving information about the set of all outside-in reduction sequences. One application would be to determine from the flow analytic information a combination of call-by-value and call-by-need which have the same termination properties as call-by-name but allow a more efficient implementation. This would extend the results of Mycroft [Myc80].

The analysis method applied the classical flow-analytic idea of abstract interpretation to a new call-by-value interpreter CBV which appears to be somewhat simpler than the SECD machine. This application required a new description technique involving both local and global data representations due to the recursiveness of CBV's data structures. The technique is applicable to many programs which manipulate tree-like data structures; it is anticipated that it can be used to develop practical interprocedural flow analysis methods for more conventional imperative programming languages. Another application would be the development of compiling methods for applicative languages capable of producing highly efficient object code.

Discussions with Flemming Nielson, David Schmidt, Peter Mosses, Mogens Nielsen and Steven Muchnick on various aspects of this work have been very helpful.

\section{REFERENCES}

Aho77 Aho, Alfred V., and Jefferey D. Ullman, Principles of Compiler Design, Reading, MA: Addison-Wesley, 1977.

Bjф78 Bjфrner, Dines and Cliff B. Jones, The Vienna Development Method: The Meta-Language, Lecture Notes in Computer Science 61 (1978).

Böh72 Böhm, Corrado and Mariangiola Dezani, "A CUCH-Machine: The Automatic Treatment of Bound Variables", Int. J. Comp. Info. Sci. vol. 1, no. 2 (1972), $171-291$. 
Cou77 Cousot, Patrick, and Radhia Cousot, "Abstract Interpretation: A Unified Lattice Model for Static Analysis of Programs by Construction of Approximation of Fixpoints", Conf. Rec. of 4th ACM Symp. on Principles of Programming Languages, Los Angeles, CA (January 1977),

Cou79 Cousot, Patrick, and Radhia Cousot, "Systematic Design of Program Analysis Frameworks", Conf. Rec. 6th ACM Symp. on Principles of Programming Languages, San Antonio, TX (January 1979), 269-282.

Cur58 Curry, Haskell B. and R. Feys, Combinatory Logic vol. 1, North-Holland, Amsterdam (1958).

Hec77 Hecht, Matthew S., Flow Analysis of Computer Programs. New York: Elsevier North-Holland, 1977.

JoM81 Jones, Neil D. and Steven S. Muchnick, "Flow Analysis and Optimization of LISP-like Structures", in Program Flow Analysis, S.S. Muchnick and N.D. Jones (eds.), Prentice-Hall (1981).

JoS80 Jones, Neil D. and Schmidt, David A., "Compiler Generation from Denotational Semantics", in Semantics-Directed Compiler Generation, Lecture Notes in Computer Science 94 (1980), 70-93.

Lan64 Landin, P.J., "The Mechanical Evaluation of Expressions", Computer Journal vol. 6, no. 4 (1964).

Lev76 Levy, J.J., "An Algebraic Interpretation of the $\lambda \beta k$-calculus and an Application of a labelled $\lambda$-calculus", Theor. Comp. Sci. vol. 2 no. 1 (1976), 97-114.

McC63 McCarthy, J., "Towards a Mathematical Science of Computation" in Information Processing, North-Holland (1963).

McG70 McGowan, C., "The Correctness of a Modified SECD Machine", Second ACM Symposium on Theory of Computation (1970).

Myc80 Mycroft, Alan, "The Theory and Practice of Transforming Call-by-need into Call-by-value", Internl. Symposium on Programming, LNCS 83 (1980), 269-281.

Ple80 Pleban, Uwe, "A Denotational Semantics Approach to Program Optimization", Ph.D. Dissertation, Univ. of Kansas, Lawrence, KS (1980). 
Plo75 Plotkin, Gordon, D., "Call-by-Name, Call-by-Value and the Lambda Calculus", Theor. Comp. Sci. 1 (1975), 125-159.

Rey72 Reynolds, John, "Definitional Interpreters for Higher-Order Programming Languages", Proc. ACM National Meeting (1972).

Ros79 Rosen, Barry K., "Data Flow Analysis for Procedural Languages", J. ACM, 26, no. 2 (April 1979), 322-344.

Sha80 Sharir, M. and A. Pnueli, "Two Approaches to Interprocedural Data Flow Analysis", Program Flow Analysis, S.S. Muchnick and N.D. Jones eds. Prentice Hall (1980).

Sin72 Sintzoff, M., "Calculating Properties of Programs by Valuation on Specific Models", Proc. ACM Conf. on Proving Assertions about Programs, New Mexico (1972), 203-207.

Ste76 Steele, Guy Lewis Jr., "LAMBDA: The Ultimate Declarative", AI Memo 379 (November 1976), Artificial Intelligence Laboratory, MIT.

Weg68 Wegner, Peter, Programming Languages, Information Structures and Machine Organization, McGraw-Hill, New York (1968). 
Lemma 1 Real $\left(\mathrm{cl}_{1}\right) \stackrel{\text { òi }}{*} \operatorname{Real}\left(\mathrm{cl}_{2}\right)$ implies Unload $\left(c\left[\mathrm{cl}_{1}\right]\right)_{\text {òi }}^{*}$ Unload $\left(c\left[\mathrm{cl}_{2}\right]\right)$.

Proof is by a simple induction on the size of $c[]$.

Lemma 2 Suppose Real $((\lambda \times M, e))=\lambda \times M^{\prime}$, Real $(c l)=N$ and $N$ is closed. Then $\operatorname{Real}((M, e\{c l / x\}))=[N / x] M^{\prime}$.

Proof is straightforward and so omitted.

Lemma $3 \quad \sigma_{1} \vec{o}_{i} \sigma_{2}$ and $\operatorname{Unload}\left(\tau_{1}\right)$ closed implies Unload $\left(\sigma_{1}\right)$ ŏ $_{i}^{*}$ Unload $\left(\sigma_{2}\right)$.

Proof If $\sigma_{1} \Rightarrow \sigma_{2}$ by transition rule $5,6,7$ on 8 then $\operatorname{Unload}\left(\sigma_{1}\right)=\operatorname{Unload}\left(\sigma_{2}\right)$ by definition of Unload. If $\sigma_{1}=c\left[\mathrm{cl}_{1}\right] \Rightarrow c\left[\mathrm{cl}_{2}\right]=\sigma_{2}$ by rule 3 or 4 then $\operatorname{Real}\left(\mathrm{cl}_{1}\right)=\operatorname{Real}\left(\mathrm{cl}_{2}\right)$ so the result holds by Lemma 1 .

If $\sigma_{1}=c\left[[(a, e)]\left(b, e^{\prime}\right)\right] \Rightarrow c\left[\left(a^{\prime},\{\}\right)\right]=\sigma_{2}$ by rule 2 then $\operatorname{Real}\left((a, e)\left(b, e^{\prime}\right)\right)=$ $a b \underset{\text { ii }}{a^{\prime}}=\operatorname{Real}\left(\left(a^{\prime},\{\}\right)\right)$. By Lemma 1, Unload $\left(\sigma_{1}\right)=\operatorname{Unload}\left(c\left[(a, e)\left(b, e^{\prime}\right)\right]\right)$ oi Unload $\left(\sigma_{2}\right)$. Finally suppose $\sigma_{1} \Rightarrow \sigma_{2}$ as in rule 1 , and let Real $((\lambda \times M, e))=\lambda \times M^{\prime}$ and Real $(c l)=N$. Unload $\left(\sigma_{1}\right)$ is closed so $N$ must also be closed. By $\beta$-reduction and Lemma 2,

$$
\operatorname{Real}((\lambda \times M, e) c l)=\left(\lambda \times M^{\prime}\right) N_{\text {oi }}[N / \times] M^{\prime}=\operatorname{Real}((M, e\{c l / x\}))
$$

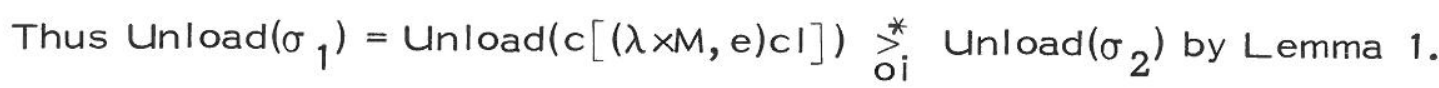

This completes the proof of part a) of Theorem 1. 1 For part b), first define a closure $(\mathrm{M}, \mathrm{e})$ to be simple if $\mathrm{M}$ is not a variable. Note that any state $\sigma=\mathrm{c}[\mathrm{cl}]$ yields a state $\sigma^{1}=c\left[\mathrm{cl}^{\prime}\right]$ with simple $\mathrm{cll}^{\prime}$ by a finite number of applications of transition rule 3 (rule 3 cannot be applied infinitely often since environments are defined inductively). A consequence is that if Real(cl) is a combination $M_{1} M_{2}$ then there exist $\mathrm{Cl}_{1}, \mathrm{cl}_{2}$ such that $\mathrm{c}[\mathrm{cl}] \underset{\mathrm{o}}{\stackrel{*}{\Rightarrow}} \mathrm{c}\left[\mathrm{cl}_{1} \mathrm{cl}_{2}\right]$ and Real $\left(\mathrm{cl}_{i}\right)=\mathrm{M}_{i}$ for $\mathrm{i}=1,2$ (since the $\mathrm{cl}^{\prime}$ mentioned above must be a combination by the definition of Real). Similar results hold if Real(cl) is an abstraction or a constant.

Part b) of Theorem 1.1 is an immediate consequence of the following.

Lemma 4 If Unload $\left(\sigma_{1}\right) \underset{\text { oi }}{\rightarrow} N$ and Unload $\left(\sigma_{1}\right)$ is closed then $\sigma_{1} \underset{\text { oi }}{\stackrel{*}{\Rightarrow}} \sigma_{2}$ for some $\sigma_{2}$ satisfying $N=\operatorname{Unload}\left(\sigma_{2}\right)$. 
Al-2

Proof It is easily seen that the inference rule for reduction in context can be replaced by the two simpler rules

$$
\text { 4'. } \frac{M_{1}>M_{2}}{M_{1} N>M_{2} N} \quad 4 \text { '!. } \frac{M_{1}>M_{2}}{N M_{1}>N M_{2}}
$$

Proof of the lemma is by induction on the number $k$ of times inference rules $4^{\prime}$ or $4^{\prime \prime}$ are used to establish Unload $\left(\sigma_{1}\right){ }_{0 \mid} \mathrm{N}$.

Basis $k=0: \quad$ Suppose Unload $\left(\sigma_{1}\right)=(\lambda \times M) N \underset{\text { oi }}{>}[N / x] M$. The following machine computation occurs:

$$
\begin{aligned}
& \sigma_{1} \underset{\mathrm{oi}}{\stackrel{*}{\Rightarrow}}[\mathrm{cl}] \quad \text { where Unload }\left(\sigma_{1}\right)=\text { Real }(\mathrm{cl}) \text { by Ol transition } \\
& \text { rules } 6,8 \\
& \stackrel{*}{\Rightarrow}\left[\mathrm{cl}_{1} \mathrm{Cl}_{2}\right] \quad \text { where Real }\left(\mathrm{cl}_{1}\right)=\lambda \times \mathrm{M}, \text { Real }\left(\mathrm{cl}_{2}\right)=\mathrm{N} \text { by rule } 3 \\
& \left.\Rightarrow \quad\left[\mathrm{Cl}_{1}\right] \mathrm{cl}_{2}\right] \quad \text { Ol rule } 5 \\
& \left.\stackrel{*}{\Rightarrow}\left[\left[\lambda \times M^{\prime}, e\right)\right] \mathrm{Cl}_{2}\right] \quad \text { where } \operatorname{Real}\left(\left(\lambda \times \mathrm{M}^{\prime}, \mathrm{e}\right)\right)=\lambda \times \mathrm{M} \text { by rule } 3 \\
& \Rightarrow \quad\left[\left(M^{\prime}, \mathrm{e}\left\{\mathrm{Cl}_{2} / \times\right\}\right)\right] \quad \text { Ol rule } 1 \\
& =\sigma_{2} \quad \text { by definition. }
\end{aligned}
$$

Now $N$ must be closed so by Lemma 2 Unload $\left(\sigma_{2}\right)=\operatorname{Real}\left(\left(\mathrm{M}^{\prime}, \mathrm{e}\left\{\mathrm{cl}{ }_{2} / \times\right\}\right)\right)=$ $[N / x] M$ as required. Delta reduction is similar but a bit simpler.

Inductive step Suppose the result holds for fewer than $k$ uses of $4^{1}$ and $4^{\prime \prime}$ where $k>0$, and Unload $\left(\sigma_{1}\right)=M_{1} M_{2}>{ }_{0 i} N M_{2}$ by $k$ uses. As in the basis case $\sigma_{1} \stackrel{*}{\Rightarrow}\left[\quad\left[\left[\mathrm{Cl}_{1}\right] \mathrm{cl}_{2}\right]\right.$ where Real $\left(\mathrm{Cl}_{i}\right)=M_{i}(i=1,2)$, by a computation involving OI transition rules $6,8,3$ and 5 . By induction $\left[\mathrm{cl}_{1}\right] \stackrel{*}{\Rightarrow} \sigma_{1}^{\prime}$ for some $\sigma_{1}^{\prime}$ with Unload $\left(\sigma_{1}{ }^{\prime}\right)=N$. By OI rules $6,8 \sigma_{1}^{\prime} \stackrel{*}{\Rightarrow}\left[c l_{1}^{\prime}\right]$ for some $c_{1}^{\prime}$ with Real $\left(c l,{ }^{\prime}\right)=N$. Finally $\left[\mathrm{cl}_{1}\right] \underset{\mathrm{oi}}{\stackrel{*}{\Rightarrow}}\left[\mathrm{cl}_{1}^{1}\right]$ implies $\left.\left[\mathrm{Cl}^{\mathrm{i}} \mathrm{cl}_{1}\right] \mathrm{cl}_{2}\right] \stackrel{*}{\stackrel{*}{\Rightarrow}}\left[\left[\mathrm{cl}_{1}^{\prime}\right] \mathrm{cl}_{2}\right] \cdot$ Let $\sigma_{2}=\left[\left[\mathrm{cl}_{1}^{1}\right] \mathrm{cl}_{2}\right]$. Clearly Unload $\left(\sigma_{2}\right)=\operatorname{Real}\left(\mathrm{cl}_{1}{ }^{\prime}\right)$ Real $\left(\mathrm{cl}_{2}\right)=\mathrm{NM}_{2}$ as required, A symmetric argument applied if Unload $\left(\sigma_{1}\right)=M_{1} M_{2}>{ }_{\text {oi }} M_{1} N$. 


\section{APPENDIX II}

\section{PROOF OF THEOREM 1.3}

We first define eval $V$ more formally just as in [Plo75]. Let "M has value $N$ at time $t^{\prime \prime}$ mean $T(M, t)=N$ where $T$ : Programs $\times\{0,1, \ldots\} \stackrel{P}{\Rightarrow}$ Programs is defined as follows.

1. $T(M, 0)=M$ if $M$ is a constant or an abstraction

2.

$$
\begin{aligned}
& \text { 2. } \frac{T\left(M_{1}, t_{1}\right)=a, T\left(M_{2}, t_{2}\right)=b \text { and Constapply }(a, b) \text { exists }}{T\left(M_{1} M_{2}, t_{1}+t_{2}+1\right)=\text { Constapply }(a, b)} \\
& \text { 3. } \frac{T\left(M_{1}, t_{1}\right)=\lambda \times M_{1}{ }^{\prime}, T\left(M_{2}, t_{2}\right)=M_{2}{ }^{\prime}, T\left(\left[M_{2}{ }^{\prime} / \times\right] M_{1}{ }^{\prime}, t_{3}\right)=N}{T\left(M_{1} M_{2}, t_{1}+t_{2}+t_{3}+1\right)=N}
\end{aligned}
$$

Now let eval $V(M)=N$ iff $T(M, t)=N$ for some $t \geq 0$, i. e. iff $M$ has value $N$ at some time. Note that $\mathrm{N}$ cannot be a combination.

Lemma 1 If Real( $\mathrm{Cl}$ ) has closed value $\mathrm{N}$ at some time then $\mathrm{CB} V$ has a computation $[\mathrm{cl}] \stackrel{*}{\Rightarrow}\left[\mathrm{Cl}^{\prime}\right]$ such that $\mathrm{N}=\operatorname{Real}(\mathrm{cl})$.

\section{Corollary 2}

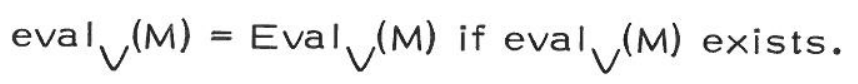

Proof Let $T(M, t)=N$ where Real $(c l)=M$. Proof is by induction on $t$. If $t=0$ it follows immediately with $\mathrm{cl}=\mathrm{cll}^{\prime}$. Now suppose $\mathrm{t}>0$ and the result holds for all times less than $t$. By definition of $T$ Real $(c l)=M_{1} M_{2}$ for some $M_{1}, M_{2}$. It is easy to see that $[\mathrm{Cl}] \stackrel{*}{\Rightarrow}\left[\mathrm{Cl}_{1}\left[\mathrm{Cl}_{2}\right]\right]$ by CBV transition rules 2,4 where $\operatorname{Real}\left(\mathrm{cl}_{\mathrm{i}}\right)=M_{\mathrm{i}}$ $(i=1,2)$.

Case $1 T\left(M_{1}, t_{1}\right)=a, T\left(M_{2}, t_{2}\right)=b, N=$ Constapply $(a, b)$ exists and $t=t_{1}+t_{2}+1$. Then $\mathrm{t}_{1}, \mathrm{t}_{2}<\mathrm{t}$ so by induction $\left[\mathrm{cl}_{1}\right] \stackrel{*}{\Rightarrow}\left[\left(\mathrm{a}, \mathrm{e}_{1}\right)\right]$ and $\left[\mathrm{cl}_{2}\right] \stackrel{*}{\Rightarrow}\left[\left(\mathrm{b}, \mathrm{e}_{2}\right)\right]$ for some $\mathrm{e}_{1}, \mathrm{e}_{2}$. Consequently CBV has the computation

$$
\begin{aligned}
{[\mathrm{cl}] } & \stackrel{*}{\Rightarrow}\left[\mathrm{cl}_{1}\left[\mathrm{cl}_{2}\right]\right] \stackrel{*}{\Rightarrow}\left[\mathrm{cl}_{1}\left[\left(\mathrm{~b}, \mathrm{e}_{2}\right)\right]\right] \Rightarrow\left[\left[\mathrm{cl}{ }_{1}\right]\left(\mathrm{b}, \mathrm{e}_{2}\right)\right] \\
& \stackrel{*}{\Rightarrow}\left[\left[\left(\mathrm{a}_{2} \mathrm{e}_{1}\right)\right]\left(\mathrm{b}, \mathrm{e}_{2}\right)\right] \Rightarrow[(\mathrm{Constapp} \mid \mathrm{y}(\mathrm{a}, \mathrm{b}),\{\})]
\end{aligned}
$$

Now let $\mathrm{cl}^{\prime}=($ Constapply $(\mathrm{a}, \mathrm{b}),\{\})$. 
All-2

Case $2 \quad T\left(M_{1}, t_{1}\right)=\lambda \times M_{1}{ }^{\prime}, T\left(M_{2}, t_{2}\right)=M_{2}{ }^{1}, T\left(\left[M_{2}{ }^{1 / x}\right] M_{1}{ }^{1}, t_{3}\right)=N$ and $\mathrm{t}=\mathrm{t}_{1}+\mathrm{t}_{2}+\mathrm{t}_{3}+1$.

Then $\mathrm{t}_{1}, \mathrm{t}_{2}<\mathrm{t}$ so by induction $\left[\mathrm{cl}_{1}\right] \stackrel{*}{\Rightarrow}\left[\mathrm{cl}_{1}^{\prime}\right]$ and $\left[\mathrm{cl}_{2}\right] \stackrel{*}{\Rightarrow}\left[\mathrm{cl}_{2}^{\prime}\right]$ where Real $\left(c \mid,{ }^{\prime}\right)=\lambda \times M_{1}{ }^{\prime}$ and Real $\left(c_{2}{ }^{\prime}\right)=M_{2}{ }^{\prime}$. Without loss of generality $c l_{1}^{\prime}=\left(\lambda \times M_{1}{ }^{\prime \prime}\right.$,e $)$ for some e, $M_{1}{ }^{\prime \prime}$. Let $\mathrm{cl}_{3}=\left(M_{1}{ }^{\prime \prime}, e\left\{c_{2}{ }^{\prime} / \times\right\}\right)$. By Lemma 2 of Appendix I, Real $\left(c_{3}\right)=$ $\left[\mathrm{M}_{2}{ }^{\prime} / \times\right] \mathrm{M}_{1}{ }^{\prime}$. Using induction again, $\left[\mathrm{Cl}_{3}\right] \stackrel{*}{\Rightarrow}\left[\mathrm{cl}{ }^{\prime}\right]$ where $\mathrm{N}=$ Real(c/'). Putting these together the required $C B V$ computation is

$$
\begin{aligned}
{[\mathrm{cl}] } & \stackrel{*}{\Rightarrow}\left[\mathrm{cl}_{1}\left[\mathrm{cl}_{2}\right]\right] \stackrel{*}{\Rightarrow}\left[\mathrm{cl}_{1}\left[\mathrm{cl}_{2}^{\prime}\right]\right] \Rightarrow\left[\left[\mathrm{cl}_{1}\right] \mathrm{cl}_{2}^{\prime}\right] \\
& \stackrel{*}{\Rightarrow}\left[\left[\left(\lambda \times \mathrm{M}_{1}^{\prime \prime}, \mathrm{e}\right)\right] \mathrm{cl}_{2}^{\prime}\right] \Rightarrow\left[\left(\mathrm{M}_{1}^{\prime \prime}, \mathrm{e}\left\{\mathrm{cl}_{2}^{\prime} / x\right\}\right)\right]=\left[\mathrm{cl}_{3}\right] \stackrel{*}{\Rightarrow}\left[\mathrm{cl}^{\prime}\right]
\end{aligned}
$$

Lemma 3 If $[\mathrm{cl}] \stackrel{*}{\Rightarrow} \sigma$, Last $(\sigma)=\sigma$ and Real $(\sigma)$ is closed then $T($ Real $(c \mid), t)=$ Unload $(\sigma)$ for some $t \geq 0$.

This result and Corollary 2 yield Theorem 1.3.

Proof Let $[\mathrm{cl}] \stackrel{\mathrm{n}}{\Rightarrow} \sigma$ where Last $(\sigma)=\sigma$, Real( $\mathrm{cl})$ is closed and $c l=(M, e)$. The result is immediate if $M$ is a constant or an abstraction, which must hold if $n=0$.

Assume inductively that the result holds for all computations of length less than $n$, where $n>0$. If $M$ is a variable then $[c l] \Rightarrow[e(M)]^{n-1} \sigma$ and Real(cl) $=$ Real(e(M)) so the result holds by induction.

The remaining case if $M=M_{1} M_{2}$, so $[\mathrm{cl}] \Rightarrow\left[\mathrm{cl}_{1}\left[\mathrm{cl}_{2}\right]\right] \stackrel{*}{\Rightarrow} \sigma$ where $\mathrm{cl}_{i}=\left(\mathrm{M}_{\mathrm{i}}, \mathrm{e}\right)$ for $\mathrm{i}=1,2$. Consider the computation $\left[\mathrm{cl}_{2}\right]=\sigma_{1} \Rightarrow \sigma_{2} \Rightarrow \ldots$. This must terminate in some $\sigma_{\mathrm{m}}$ without an "error stop", else $[\mathrm{cl}] \stackrel{*}{\Rightarrow} \sigma$ is violated. It is easy to see that $\sigma_{m}=\left[\mathrm{Cl}_{2}{ }^{\prime}\right]$ where $\mathrm{cl}_{2}{ }^{\prime}=\left(\mathrm{M}_{2}{ }^{\prime}, \mathrm{e}_{2}\right)$ for some value $\mathrm{M}_{2}{ }^{\prime}$. Thus the computation may be refined fur ther:

$$
[\mathrm{cl}] \stackrel{*}{\Rightarrow}\left[\mathrm{cl}_{1}\left[\mathrm{cl}_{2}\right]\right] \stackrel{\mathrm{n}_{2}}{\Rightarrow}\left[\mathrm{cl}_{1}\left[\mathrm{cl}_{2}^{\prime}\right]\right] \Rightarrow\left[\left[\mathrm{cl}_{1}\right] \mathrm{cl}_{2}^{\prime}\right] \stackrel{*}{\Rightarrow} \sigma
$$

Since $\mathrm{n}_{2}<\mathrm{n}$ and Last $\left(\left[\mathrm{Cl}_{2}^{\prime}\right]\right)=\left[\mathrm{Cl}_{2}{ }^{\prime}\right]$ we may use induction to show that $T\left(\right.$ Real $\left.\left(\mathrm{Cl}_{2}\right), \mathrm{t}_{2}\right)=\operatorname{Real}\left(\mathrm{cl}_{2}{ }^{1}\right)$ for some $\mathrm{t}_{2}$.

By exactly the same reasoning applied to $\mathrm{Cl}_{1}$ there must exist $\mathrm{Cl}_{1}{ }^{\prime}=\left(\mathrm{M}_{1}{ }^{1}, \mathrm{e}_{1}\right), \mathrm{t}_{1}$ such that $\left[\mathrm{Cl}_{1}\right] \stackrel{*}{\Rightarrow}\left[\mathrm{Cl}_{1}^{\prime}\right]$ and $T\left(\operatorname{Real}\left(\mathrm{cl}_{1}\right), \mathrm{t}_{1}\right)=\operatorname{Real}\left(\mathrm{Cl}_{1}{ }^{\prime}\right)$. The computation may be re-expressed:

$$
[\mathrm{cl}] \stackrel{*}{\Rightarrow}\left[\left[\mathrm{Cl}_{1}^{1}\right] \mathrm{cl}_{2}^{\prime}\right] \stackrel{*}{\Rightarrow} \sigma
$$


Case $1 \quad M_{1}{ }^{\prime}$ is a constant a.

Since the computation terminates $M_{2}{ }^{\prime}$ must be a constant $b$ such that Constapply $(a, b)$ exists. By inference rule 2 of the definition of $T$

$T\left(\right.$ Real $\left.(c l), t_{1}+t_{2}+1\right)=T\left(\right.$ Real $\left(c_{1}\right)$ Real $\left.\left(c_{2}\right), t_{1}+t_{2}+1\right)=$ Constapply $(a, b)$

Case $2 \quad M_{1}{ }^{\prime}$ is an abstraction $\lambda \times M_{1}{ }^{\prime \prime}$.

By CBV transition rule $1[\mathrm{cl}] \stackrel{*}{\Rightarrow}\left[\left[\mathrm{cl}_{1}^{\prime}\right] \mathrm{cl}_{2}^{\prime}\right] \Rightarrow\left[\left(\mathrm{M}_{1}{ }^{\prime \prime}, \mathrm{e}\left\{\mathrm{cl}_{2}{ }^{\prime} / \mathrm{x}\right\}\right)\right]=\left[\mathrm{cl}_{3}\right]^{\mathrm{n}_{3}} \Rightarrow \sigma$ where $\mathrm{n}_{3}<\mathrm{n}$. By induction $T\left(\right.$ Real $\left.\left(\mathrm{cl}_{3}\right), \mathrm{t}_{3}\right)=$ Unload $(\sigma)$ for some $t_{3}$. Let Real $\left(\mathrm{cl}_{1}{ }^{\prime}\right)=$ $\lambda \times M_{1}{ }^{\prime \prime \prime}$. By Lemma 2 of Appendix 1

$\operatorname{Real}\left(\mathrm{cl}_{3}\right)=\left[\operatorname{Real}\left(\mathrm{cl}_{2}{ }^{\prime}\right) / \times\right] M_{1}^{\prime \prime \prime}$

By inference rule 3 of the definition of $T, T\left(\right.$ Real $\left.(c l), t_{1}+t_{2}+t_{3}+1\right)=$ Unload $(\sigma)$. 